\title{
La influencia “artística” de las emociones y la empatía en el contenido, la interpretación y la efectividad del derecho internacional
}

\author{
The "Artistic" Influence of Emotions and Empathy \\ in the Content, Interpretation and Effectiveness \\ of International Law
}

\section{Nicolás Carrillo Santarelli*}

SUMARIO: I. Introducción. II. La sinergia entre las emociones y el derecho internacional. III. La creación e interpretación emotivas del derecho internacional. IV. El papel de las emociones y las estrategias emotivas en la legitimación y efectividad de procesos jurídicos internacionales. V. Conclusiones. VI. Bibliografía.

* Profesor de Derecho Internacional de la Universidad de La Sabana, Colombia. Doctor en Derecho Internacional y Relaciones Internacionales por la Universidad Autónoma de Madrid, y Diploma de Estudios Avanzados en Derecho Internacional y Relaciones Internacionales de la misma Universidad; maestría en Protección de los Derechos Humanos de la Universidad de Alcalá, y licenciado en Derecho de la Universidad Externado de Colombia. 
RESUMEN: Las emociones integran una de las dimensiones de las experiencias y actividades humanas, y ello explica su posible incidencia en la interacción de distintos actores con el derecho internacional, que es una construcción social en cuya evolución y creación han incidido no sólo argumentos racionales sino además posturas emotivas, que en la práctica pueden incidir no sólo en la creación, sino, además, en la interpretación o invocación e incluso en la efectividad y legitimidad de aquel derecho, máxime cuando tanto las emociones como el derecho internacional ofrecen lenguajes mundiales. Ello explica el empleo de distintas estrategias emotivas, formales o no, jurídicas y extrajurídicas, como el cine, el arte o actividades lúdicas, por parte de quienes interactúan con el derecho internacional, en tanto los discursos jurídicos con tintes emotivos pueden hacer a sus destinatarios más proclives a acoger sus discursos, que al entrañar un intento de transmitir emociones pueden calificarse de "artísticos". Estos discursos acarrean riesgos cuando procuren desconocer derechos de minorías pero ofrecen la promesa de "humanizar" el derecho si se fundamentan en la empatía, que al llevar al intérprete a asumir la posición de las víctimas puede identificar sus necesidades de protección jurídica tanto en la lex lata como en la lex ferenda.

Palabras clave: emociones, derecho internacional, función simbólica, efectividad, actores no estatales.

ABSTRACT: emotions are part of the multiple dimensions of human experience and activities. International Law, as a social construction, is thus prone to be subject to its influence. Such influence can be channeled by different participants which interact with that law in processes of legal creation, invocation or interpretation, taking advantage of the universal language of international law and enhancing their discourses with emotional overtones. Furthermore, certain emotional strategies, with can either employ legal or extra-legal vessels as movies, art or games can either generate empathy, promoting changes in normative contento or action in order to have solidarity with those who suffer; or to increase or affect the effectiveness of international law.

Key words: emotions, international law, expressive effects, effectiveness, non-state actors.

RÉSUMÉ: les émotions intègrent une des dimensions de l'activité et de l'expérience humaines et ceci explique leur possible incidence sur l'interaction de différents acteurs dans le droit international. Construction sociale, la création et l'évolution du droit international n'a pas suscité simplement des arguments rationnels mais également des postures émotives qui peuvent, dans la pratique, influencer la création mais aussi l'interprétation, le recours, voire même l'efficacité et la légitimité dudit droit qui n'est jamais aussi puissant que lorsque ces émotions et ce droit international sont exprimés dans des langues comprises dans le monde entier. D'où l'utilisation de diverses stratégies émotives, formelles ou pas, parfois juridiques, comme le cinéma, l'art ou les activités ludiques par ceux qui interagissent avec le droit international. Car les discours juridiques qui font la part belle à l'émotion peuvent influencer leurs destinataires en leur faisant mieux accepter les opinions avancées alors que lorsque d'autres discours qui tentent de transmettre des émotions sont considérés comme « artistiques». Ces derniers ne sont pas sans risque lorsqu'ils ignorent délibérément les droits de minorités mais promettent «d'humaniser» le droit en adoptant une posture pleine d'empathie. L'interprète est alors amené à assumer la position des victimes et à identifier ses besoins en matière de protection juridique, tant dans la lex lata que dans la lex ferenda.

Mots-clés: émotions, droit international, fonction symbolique, efficacité, acteurs non étatiques. 


\section{INTRODUCCIÓN}

Según el gran autor ruso Tolstói, como se describe más abajo en este texto, toda actividad que logre o procure la transmisión de sentimientos o emociones se puede identificar como artística. Esta identificación abre las puertas a un interesante universo sobre las múltiples maneras en las que las emociones pueden incidir en los distintos mecanismos de interacción con el derecho internacional llevados a cabo por distintos actores, como agentes estatales, de organizaciones internacionales o incluso ONG o individuos, que interactúan con aquel derecho formal o informalmente con el propósito (consciente o no) de alcanzar o facilitar determinados objetivos mediante su invocación.

¿Por qué motivo? Sencillamente porque aquellos participantes pueden llamar la atención sobre la importancia emocional de que se acoja su propuesta de lege ferenda o de interpretación del derecho internacional positivo, en tanto un discurso emotivo puede hacer más factible que las respectivas audiencias o autoridades favorezcan su postura. Aquella apelación emocional puede ser honesta, cuando el participante realmente sienta y transmita las emociones que experimentan los individuos que integran el respectivo actor, o meramente estratégica, cuando sea una interpelación realizada de forma emotiva porque se espera que ello facilite la manipulación de la audiencia.

En consecuencia, las emociones se pueden emplear o transmitir con intenciones o consecuencias positivas o negativas desde el punto de vista de derechos de las minorías u otras perspectivas, como la ética, como se discute más adelante a propósito del Brexit o los intentos de "embellecer" el waterboarding, entre otras prácticas odiosas. Dicho esto, desde un punto de vista positivo, las emociones pueden incrementar o activar nuestra empatía, que supone el ponernos en el lugar de quien sufre o padece negaciones a su dignidad o valor intrínseco.

De esta manera, la empatía puede generar tanto iniciativas para adoptar normas consuetudinarias o convencionales que protejan a aquellos afectados como favorecer la interpretación de normas actuales fundadas en aquella dignidad para lograr un fin protector, por ejemplo, cuando tengan una 
Esta revista forma parte del acervo de la Biblioteca Jurídica Virtual del Instituto de Investigaciones Jurídicas de la UNAM www.juridicas.unam. $m x$

textura muy abierta o indeterminada. ${ }^{1}$ La mención a la empatía y a la dignidad nos ofrecen un criterio: las emociones que las desconozcan y vulneren han de ser rechazadas en las interacciones jurídicas, que deben proteger a las minorías y a todo ser humano, incluso frente a llamamientos apasionados a agredirles; mientras que los sentimientos de solidaridad, como se dirá abajo en el texto, han de ser acogidos y pueden guiar la evolución y el desarrollo progresivo del derecho internacional y su humanización. En consecuencia, así como se estima que en la política no se puede decir que las emociones sean rechazadas o bienvenidas por el simple hecho de ser tales, sino que la apertura a su influencia dependerá de su dinámica (rechazo si se llama a la venganza e ira o a la discriminación; bienvenida si se alude a la tolerancia o a la protección de quien sufre, caso en el que son compatibles con la razón, ${ }^{2}$ idea que se repite más adelante), algo similar puede decirse sobre las emociones en el derecho internacional, que pueden influir formal o informalmente, con límites y en distintas dinámicas, en formas como las que se estudian en este texto.

Por lo expresado hasta el momento, se puede decir que las emociones pueden tener un papel en las distintas interacciones con la lex lata, incluyendo operaciones de interpretación, adjudicación o invocación, entre otras; debido a la influencia de los seres humanos que, como revela cualquier análisis desagregado, integran los actores colectivos (o individuales) que se relacionan con el derecho internacional, en tanto esos seres humanos, multidimensionales, tienen emociones y sentimientos. Siendo así las cosas, podría decirse que la influencia directa o indirecta, sutil o abierta de las emociones en las interacciones con el derecho son “artísticas", porque entrañan la transmisión de emociones, o el intento o potencialidad de llevarla a cabo.

Dicho esto, ¿tiene sentido hablar de emociones en las interacciones con el derecho internacional? ¿No es el mismo una disciplina u ordenamiento jurídico "racional” que está llamado a excluir la influencia de las intuiciones o emociones? En modo alguno. Al respecto, estudios psicológicos o sobre las emociones, como indica Evans, han llamado la atención sobre su relevancia en distintas actividades humanas y, en consecuencia, han contribuido a que el estudio de las emociones haya dejado de ser un monopolio de algu-

1 Kidd White, E., “Till Human Voices Wake Us”, Journal of Law, Religion and State, vol. 3, 2012, p. 212.

2 Clarke, S. et al., “The Study of Emotion: An Introduction”, en Clarke, S. et al. (eds.), Emotion, Politics and Society, Nueva York, Palgrave Macmillan, 2006, pp. 3-5. 
Esta revista forma parte del acervo de la Biblioteca Jurídica Virtual del Instituto de Investigaciones Jurídicas de la UNAM

nas pocas disciplinas, como la psicología o la antropología. ${ }^{3}$ Esta expansión es acertada, en tanto los seres humanos tenemos múltiples dimensiones con frecuencia entrelazadas - ${ }^{4}$ siendo la emocional una de ellas.

Quienes nos dedicamos al estudio del derecho internacional, también debemos preguntarnos si, y qué papel juegan las emociones, en tanto aquel derecho, según la máxima sic societas sicut jus, ha de responder a realidades y necesidades sociales internacionales, ${ }^{5}$ muchas de las cuales, como el drama de los refugiados o de las víctimas de agresiones sexuales, o bien entrañan problemas emocionales o son discutidas con argumentos e interpelaciones que tienen, no sin razón, una gran carga emotiva, como sucede con apelaciones empáticas.

$\mathrm{Al}$ respecto, ha de decirse que la empatía cumple un papel importante en tanto, al ubicarse en la situación de los demás, puede inspirar cambios en la forma en la que el derecho responde a las necesidades y sufrimientos de nuestros congéneres. En este sentido, algunos desarrollos jurídicos internacionales como los del derecho internacional humanitario tienen un trasfondo emocional y empático, como demuestra su impulso solidario por Henry Dunant. ${ }^{6}$ Además de influir en la formación del derecho internacional, las emociones también pueden estar presentes en las reacciones emotivas a su contenido y aplicación y, como acontece con toda actividad humana, en su posible influencia en la forma en que distintos actores interactúan con el derecho internacional - si ello es adecuado o no es otra cuestión, que puede estar relacionada con el respeto del rule of law y principios tanto de debido proceso como de justicia sustantiva-.

En consecuencia, sería un error desdeñar el papel que pueden y deben tener las emociones y la empatía en los procesos de interacción con el derecho internacional, tanto los relativos a su aplicación como los relacionados con su transformación. Este artículo se ocupa de estas cuestiones, de la siguiente manera: en primer lugar, el artículo estudia porqué motivo las emociones no son ajenas al derecho internacional, que se ha formado por iniciativas tanto académicas como diplomáticas en las que las emociones han

3 Evans, D., Emotion: A Very Short Introduction, Oxford, Oxford University Press, 2003.

4 Goldie, P., The Emotions: A Philosophical Exploration, Oxford, Oxford University Press, 2002, pp. 3-5, 27, 232.

5 Remiro, A. et al., Derecho Internacional, Valencia, Tirant lo Blanch, 2007, p. 46.

6 Kalshoven, F. y Zegveld, L., Constraints on theWaging of War, Ginebra, Comité Internacional de la Cruz Roja, 2001, p. 26. 
Esta revista forma parte del acervo de la Biblioteca Jurídica Virtual del Instituto de Investigaciones Jurídicas de la UNAM

podido tener cierto influjo, al menos selectivo o que refleje cambios en las percepciones y actitudes emotivas, al igual que ha ocurrido en los ámbitos internos, ${ }^{7}$ y cómo de hecho las emociones pueden ayudar a realizar ciertas interpretaciones complejas y difuminar o atenuar los riesgos de fragmentación y están además presentes en las perennes evaluaciones críticas de los internacionalistas sobre el derecho positivo.

Posteriormente, se examinará cómo las autoridades u operadores jurídicos, incluidos los jueces, pueden obrar bajo cierto influjo emocional al interpretar, aplicar, invocar o decidir sobre el derecho o problemas jurídicos, e incluso cómo en la creación del derecho internacional la causa remota o material, es decir, la "inspiración” de la legislación según los británicos, puede ser al menos en parte emocional, como ha sucedido con las iniciativas que han llamado al fin de la impunidad o la protección de ciertas personas vulnerables, cuya presión social (de individuos, ONG y otros integrantes de la sociedad civil) ha culminado en tratados como el Estatuto de Roma o la Convención contra la Tortura.

Por último, tras examinar la relevancia general de las emociones en el derecho internacional (con sus límites) en la primera sección y su influencia en la creación e interpretación del derecho internacional en la segunda sección, se culminará el artículo analizando otra posible incursión emocional en el derecho internacional a través de los operadores jurídicos, que en últimas están compuestos por individuos: su legitimidad y efectividad. Esto se debe a que, como se explicará, la afinidad emocional con lo que disponga el derecho según los intérpretes y el público podrá incrementar la disposición a cumplirlo incluso si ello acarrea costos.

A su vez, ello explica cómo puede haber distintas estrategias jurídicas y extrajurídicas que, al incidir sobre la percepción emocional del derecho, afecten su efectividad. Aquellas actividades incluyen actividades y obras como la literatura, el cine, los videojuegos incluso y las campañas en redes sociales, que al interesarse cada vez más sobre aspectos o bienes jurídicos regulados o protegidos por el derecho internacional motivan a un público mayor y no necesariamente especializado a promover determinadas políticas o acciones relacionadas con el derecho internacional. Estas iniciativas pueden tener efectos positivos o negativos, por ejemplo, si logran educar

7 Sajó, A., "Emotions in Constitutional Design", International Journal of Constitutional Law, vol. 8, 2010, pp. 372, 377, 379, 383. 
Esta revista forma parte del acervo de la Biblioteca Jurídica Virtual del Instituto de Investigaciones Jurídicas de la UNAM

sobre el contenido jurídico y sus razones últimas de forma acertada o errónea, o si promueven el apoyo al derecho que protege al débil o la toma de decisiones de forma impulsiva o apresurada.

\section{LA SINERGIA ENTRE LAS EMOCIONES Y EL DERECHO INTERNACIONAL}

A primera vista, podría pensarse que la relación entre las emociones y el derecho internacional es mínima o incluso nula, en tanto el estudio del derecho suele concebirse como una tarea racional. ${ }^{8}$ Un estudio de la práctica y la teoría podría sugerir esto, en tanto los tratados de Grocio, Vitoria, Gentili, Vattel y otros son importantes tareas intelectuales. Si se acoge una idea que conciba a la práctica jurídica internacional como una ciencia pura o semejante en cierto modo a las ciencias naturales, ${ }^{9}$ como apunta Feldam, puede resultar tentador excluir la relevancia de las emociones, ${ }^{10}$ que incluso se podrían concebir como corruptoras de una aplicación "pura" del derecho, evocando la eterna duda sobre si las emociones o los sentimientos entran en conflicto con la razón, como se sugirió por el romanticismo. ${ }^{11}$

Sin embargo, son conocidos los análisis críticos que indagan cómo las propuestas teóricas de aquellos autores entrañaban, de forma consciente o inadvertida, una toma de posturas que favorecía determinadas posiciones, bien sea políticas, por ejemplo, para promover una libertad de los mares que favorecía a Holanda; ideológicas, como cuando Vattel deseaba proteger a las repúblicas frente a amenazas imperiales, o religiosas, como revela la apuesta por una concepción naturalista de algunos autores que incluso tenían votos religiosos. ${ }^{12}$

8 Como bien se describe en la convocatoria de ponencias para el coloquio "Emociones y derecho internacional", disponible en: http://www.derecho.uba.ar/investigacion/2016_colo quio-sobre-emociones-convocatoria-de-ponencias.pdf.

9 Kelsen, H. Pure Theory of Law, Nueva Jersey, The Lawbook Exchange, Ltd., 2008, pp. 1, 70-75.

10 Feldam, H., "Foreword: Law, Psychology, and the Emotions", Chicago-Kent Law Review, vol. 74, 2000, p. 1424.

11 Evans, D, op. cit.

12 Koskenniemi, M., "Histories of International Law: Significance and Problems for a Critical View", Temple International and Comparative Law Journal, vol. 27, 2013, pp. 217-218, 227 - 
Esta revista forma parte del acervo de la Biblioteca Jurídica Virtual del Instituto de Investigaciones Jurídicas de la UNAM

Si admitimos que a través de personas influyentes aquellas posturas inciden en la concepción y práctica del derecho internacional, ¿acaso se puede negar que las posturas políticas, religiosas, ideológicas o de otra índole pueden entrañar pasiones y emociones y que éstas pueden tener dimensiones políticas o de otra índole ? $^{13}$ — de hecho, algunos grupos admiten de forma abierta que estratégicamente emplean discursos apasionados- $-{ }^{14}$ Un ejemplo interesante se nos ofrece en los votos y discursos de los jueces, contemporáneamente, entre otros, en la figura de Antonio Cançado, el jurista brasileño que ha desempeñado importantes cargos en órganos como la Corte Interamericana de Derechos Humanos o la misma Corte Internacional de Justicia, en tanto sus elucubraciones claramente humanistas le llevan a interpretaciones del derecho positivo fuertemente influenciadas por sus convicciones.

Algunas posturas realistas sugieren ${ }^{15}$ que no siempre, pero sí en ocasiones, las conclusiones de los operadores jurídicos y de académicos pueden estar más o menos bajo el influjo de emociones como la indignación o la solidaridad, los sentimientos que despierte un caso o el apasionamiento de los discursos de los abogados; aunque algunos autores señalan que si bien esto es plausibe no hay que generalizar, sino que se debe indagar por las emociones de cada actor en concreto. ${ }^{16}$

Las emociones, de hecho, no pueden ser sólo relevantes en la etapa de aplicación del derecho, sino que, además, han inspirado desarrollos y cambios en el ámbito de los derechos humanos, como apunta Clapham. ${ }^{17}$ Esta influencia no es necesariamente consciente, pero se explica en tanto las concepciones y posturas de los seres humanos pueden tener un impacto en la forma en que se concibe y, en consecuencia, se aplica el derecho in-

228, 232, 240; Lee, T., "International Law, International Relations Theory, and Preemptive War: The Vitality of Sovereign Equality Today”, Law and Contemporary Problems, vol. 67, 2004, pp. 150-152.

13 Goldie, P., op. cit., p. 27.

14 Miller, D., Political Philosophy:A Very Short Introduction, Oxford, Oxford University Press, 2003.

15 Tumonis, "Legal Realism \& Judicial Decision-Making”, Jurisprudencija /Jurisprudence, vol. 19, 2012, pp. 1369, 1376-1377.

16 Feldam, H., op. cit., pp. 1423, 1425-1426.

17 Clapham, A., Human Rights: A Very Short Introduction, Oxford, Oxford University Press, 2015, pp. xiii, 22, 24, 164-165. 
Esta revista forma parte del acervo de la Biblioteca Jurídica Virtual del Instituto de Investigaciones Jurídicas de la UNAM

ternacional, según han explicado autores como Klabbers. ${ }^{18}$ Por ejemplo, la concepción contemporánea de la dignidad humana, decisiva en el derecho internacional de los derechos humanos, ${ }^{19}$ es preponderantemente intuitiva. ${ }^{20}$ Ello abre la puerta a la indignación y a la empatía, como dice Kidd White, pues la "delgadez" o poca concreción de la noción permite que el intérprete apoye o experimente rechazo a determinadas agresiones o la solidaridad con quien sufre.

Estas dinámicas son importantes pues permiten identificar qué problemas merecen una atención especial - función de conocimiento del otro y su situación-e inspirar acciones en consecuencia, como indica D'Arms. ${ }^{21}$

Sin embargo, sería erróneo decir que las emociones necesariamente suplantan o determinan plenamente los procesos de interacción con el derecho internacional, en tanto hay límites y contenidos que no se pueden ignorar por más insatisfacción que haya con los mismos, so pena de incurrir en abuso o desviación de poder; esto acotece si una autoridad desea transplantar o reemplazar el derecho positivo por intuiciones emotivas praeter o contra legem, será evidente que está transgrediendo su mandato de velar por el cumplimiento del derecho y se expondrá a sanciones o reproche ${ }^{22}$ - aunque su posición le llama a asumir la responsabilidad ética de analizar críticamente el derecho y llamar la atención sobre puntos de mejora-.

En los eventos en que "su corazón" y el derecho se contradigan, lo más honesto y conveniente es que los agentes critiquen al derecho positivo y propongan alternativas de lege ferenda. Desde la antigüedad, como demues-

18 Klabbers, J., International Law, Cambridge, Cambridge University Press, 2013, pp. 3 y 4; Losano, M., "Towards a Common Good: A Path to Utopia? From Philosophy through Legislation to the Dignified Life", European Journal of Law Reform, vol. 6, 2004, pp. 329-330.

19 Andorno, R., "Human Dignity and Human Rights as a Common Ground for a Global Bioethics", Journal of Medicine and Philosophy, vol. 34, 2009, pp. 228-234.

20 Sensen, O., "Human Dignity in Historical Perspective: The Contemporary and Traditional Paradigms”, European Journal of Political Theory, vol. 10, 2011, pp. 72-73, 85.

21 D’Arms, J., "Empathy and Evaluative Inquiry”, Chicago-Kent Law Review, vol. 74, 2000, pp. 1469, 1494; Feldam, H, op. cit., p. 1427.

22 Corte IDH, Caso Granier y otros (Radio Caracas Televisión) vs. Venezuela, excepciones preliminares, fondo, reparaciones y costas, sentencia del 22 de junio de 2015, serie C, núm. 293, párrs. 189, 193, 197-198; Carrillo-Santarelli, N. y Espósito, C., "The Protection of Humanitarian Legal Goods by National Judges”, European Journal of International Law, vol. 23, 2012, pp. 68, 76, 82-85, 95. 
Esta revista forma parte del acervo de la Biblioteca Jurídica Virtual del Instituto de Investigaciones Jurídicas de la UNAM

tran las obras Antígona y Epitrepontes, ${ }^{23}$ ha habido cuestionamientos tanto sobre la justicia del derecho positivo — pudiéndose basar aquellos cuestionamientos en sentimientos que afloran al comparar al derecho con estándares no necesariamente racionalizados sobre lo justo e injusto- como sobre la contradicción entre lo que permite o dice el derecho y los sentimientos de los implicados en un caso, e ignorar aquellas indagaciones puede redundar en perjuicio de la legitimidad del derecho internacional y, en consecuencia, de su efectividad, dada la menor probabilidad de que un derecho rechazado o criticado sea respetado. ${ }^{24}$

Además de jugar un papel en la crítica y legitimidad del derecho internacional, las emociones pueden tener, y de hecho han tenido, un rol en su implementación y transformación en menor o mayor medida. En consecuencia, no ha de sorprender que existan estrategias que buscan generar determinadas emociones para influir en los procesos jurídicos internacionales, lo cual puede ser conveniente o no, según el caso. Como se examina en este escrito, aquellas estrategias pueden ser tanto jurídicas, incluyendo la participación formal e informal de diversos actores, estatales y no estatales; como extrajurídicas, incluyendo actividades artísticas y lúdicas. Siendo esto así, se podría decir que los distintos participantes que buscan influir en los procesos jurídicos internacionales de forma emotiva operan como artistas, debido a que, como dijo Tolstói en ¿Qué es el arte?, el arte puede considerarse como una actividad de transmisión o inspiración de emociones. ${ }^{25}$ Curiosamente, ya se ha indagado — por ejemplo, por Dworkin — si la interacción con el derecho puede asemejarse a la literatura, particularmente en cuanto a la labor de interpretación, ${ }^{26}$ que como se comenta más adelante puede abrir las puertas a cierto juego de las emociones.

Mediante discursos emotivos y narrativas con carga emocional, los participantes que interactúan con el derecho internacional pueden incidir en la generación de nuevas actitudes o percepciones sobre la realidad y la re-

23 Buis, E., "Law and Greek Comedy", en Fontaine, M. y Scafuro, A. (eds.) The Oxford Handbook of Greek and Roman Comedy, Nueva York, Oxford University Press, 2014, p. 335-336; Voto razonado del juez A.A. Cançado Trindade a: Corte IDH, Caso Bámaca Velásquez vs. Guatemala, fondo, sentencia del 25 de noviembre de 2000, serie C, núm. 70, párrs. 8-9.

${ }^{24}$ Koh, H., "Why Do Nations Obey International Law?", The Yale Law Journal, vol. 106, 1997, p. 2601.

25 Tolstói, L., What is Art, Indianápolis, Hackett Publishing Company, Inc., 1996.

26 Dworkin, R., "Law as Interpretation”, Critical Inquiry, vol. 9, pp. 179, 182-200. 
Esta revista forma parte del acervo de la Biblioteca Jurídica Virtual del Instituto de Investigaciones Jurídicas de la UNAM

gulación que tienen o deben tener determinados problemas. Esto se debe a una curiosa confluencia entre las dinámicas de las emociones y del derecho internacional: la universalidad. Al referirme a este término en este contexto no me refiero la idea de que hay normas obligatorias en todo rincón del planeta, función que cumple por el momento el derecho imperativo, al vincular a todo sujeto capaz de violarlo de forma expresa o implícita. ${ }^{27}$ Por el contrario, me refiero a la noción de un lenguaje universal que pueda emplearse para describir y discutir sobre la realidad mundial y tomar decisiones.

$\mathrm{Al}$ respecto, es pertinente mencionar que el derecho internacional, según describe Klabbers, opera como un idioma común que abarca conceptos que permiten referirse a la sociedad mundial, sus valores, problemas y estándares. ${ }^{28}$ En cuanto a las emociones, por su parte, estudios actuales desmienten que haya una relatividad absoluta según la cual cada cultura o sociedad tiene distintos manejos emocionales, sugiriendo por el contrario que puede haber algunas reacciones emotivas universales, explicadas en parte por aspectos como la evolución. ${ }^{29}$ Siendo esto así, no debe sorprender que distintos actores, tanto estatales como no estatales, desplieguen iniciativas para apropiarse del idioma jurídico universal que ofrece el derecho internacional enviando mensajes emotivos ${ }^{30}$ para convencer a un amplio público y reforzar sus demandas y objetivos, como la modificación o preservación del estatus quo — normativo o social — en determinado aspecto. ${ }^{31}$

Lo anterior refleja una posible confluencia entre las dimensiones jurídica y emocional, en tanto enviar mensajes apasionados o emotivos puede contribuir a reforzar interpretaciones o posturas sobre el derecho internacional, y en concreto los mensajes empáticos pueden ser "contagiosos" en la transmisión de mensajes emocionales. ${ }^{32}$ Adicionalmente, en tanto en ocasiones aquel derecho maneja conceptos amplios o ambiguos, ${ }^{33}$ las ape-

27 Carrillo-Santarelli, N., "The Necessity and Possibility of a Binding Approach to International Corporate Human Rights Responsibilities”, Quaestio Iuris, vol. 8, 2015, pp. 432-435.

28 Klabbers, J., op. cit., pp. 16, 309, 315.

29 Evans, D., op. cit.

30 Simpson, G. "The Sentimental Life of International Law", London Review of International Law, vol. 3, 2015, pp. 4-6, 9, 15, 17-18, 22.

31 Klabbers, J., op. cit., pp. 308-309.

32 D’Arms, J., op. cit., p. 1495.

33 Posner, E., The Perils of Global Legalism, Chicago, The University of Chicago Press, 2009, pp. 20, 111-112, 106, 206, 217. 
Esta revista forma parte del acervo de la Biblioteca Jurídica Virtual del Instituto de Investigaciones Jurídicas de la UNAM

laciones emotivas pueden facilitar arribar a determinadas interpretaciones. Ello se facilita cuando haya cabida a interpretaciones evolutivas o cuando se envíen mensajes con una carga emotiva fuerte que pueda inclinar a algunos a preferirlas a posturas "más frías", y explica la actitud de actores como ONG o ciertos Estados de apelar a la solidaridad o a la empatía con las víctimas para promover determinada interpretación o implementación. Esto es meridiano cuando se emplea la técnica del avergonzamiento ${ }^{34}$ de presuntos abusadores, al buscarse generar la indignación de los demás con el fin de que ellos ejerzan presión sobre el acusado y lo lleven a cesar o desistir de un abuso.

Con todo, hay que advertir un par de cosas. En primer lugar, que muchos operadores jurídicos, como, por ejemplo, quizás en ocasiones en el ámbito del derecho internacional económico y su derecho de las inversiones extranjeras, pueden optar por actitudes que no tengan muy presente el sufrimiento o los problemas generados por una aplicación excesivamente técnica del derecho, especialmente cuando esos regímenes se usan de forma hermética, prácticamente como self-contained regimes de forma fragmentadora, ignorando no sólo otras normas internacionales sino además interpretaciones alternativas admisibles que tengan más en cuenta el sufrimiento o los problemas de terceros: por ello, la empatía puede contribuir, junto a otros factores, a incluir consideraciones humanitarias (que afortunadamente se consideraron en cuanto al derecho a la salud en el Caso Philip Morris contra Uruguay). ${ }^{35}$

En segundo lugar, se puede decir que las dinámicas que incorporan un discurso emocional no están exentas de riesgos o complejidad, pues es posible que quienes promueven determinada postura por razones emotivas tengan contrapartes con argumentos que también tengan una inspiración emocional, quizá tan o más válida. Ello exige permitir y fomentar los debates y discusiones entre distintos actores, por ejemplo, entre distintas ONG

34 Meernik, J., Aloisi, R., Sowell, M. et al., "The Impact of Human Rights Organizations on Naming and Shaming Campaigns", Journal of Conflict Resolution, vol. 56, 2012, pp. 233 237, 245, 252-253.

35 Nicolás Carrillo Santarelli, "Una victoria para el derecho a la salud sobre intereses (egoístas) económicos: la decisión sobre inversiones extranjeras en el caso Philip Morris vs. Uruguay", Aquiescencia, 12 de julio de 2012, disponible en: https://aquiescencia. net /2016/07 / 12 / una-victoria-para-el-derecho-a-la-salud-sobre-intereses-egoistas-economicos-ladecision-sobre-inversiones-extranjeras-en-el-caso-philip-morris-vs-uruguay/ (fecha de consulta: 19 de agosto de 2016). 
Esta revista forma parte del acervo de la Biblioteca Jurídica Virtual del Instituto de Investigaciones Jurídicas de la UNAM

e incluyendo a Estados, académicos y otros actores con posturas disímiles, en tanto el intercambio de opiniones y la libertad de expresión pueden contribuir a decantar qué postura es la más apropiada ${ }^{36}$ incluso en términos emocionales. Por ende, es comprensible el rechazo a las exclusiones de ONG en el Ecosoc motivadas por desacuerdos políticos, ${ }^{37}$ pues ello empobrece el debate y genera riesgos de que se escuchen única o preponderantemente algunos discursos, apasionados o no.

Al respecto, cabe recordar que el denominado Lawfare y los llamados "combates psicológicos" se basan en la idea de que distintos actores buscan promover sus objetivos políticos o de seguridad, que pueden ser emotivos, revistiéndolos con un lenguaje jurídico internacional, para influir, entre otras en las emociones de sus audiencias, ${ }^{38}$ lo que estimula a sus contrapartes a adoptar discursos similares, aparentemente basados en nociones jurídicas para defender ciertas posturas de forma emotiva.

En consecuencia, los discursos con cargas emotivas no deben aceptarse automáticamente, pues deben contrastarse con otros. Además, conviene examinarlos de forma racional, pues las emociones y la racionalidad son dimensiones complementarias de las actividades, cualidades y experiencias humanas. ${ }^{39}$ Esto permite prevenir manipulaciones sentimentales que buscan beneficiar determinados intereses ignorando el sufrimiento causado a otros, algo que condena la Declaración Universal de Derechos Humanos, ${ }^{40}$ $\mathrm{y}$, además, permite evitar dinámicas de path dependency, ${ }^{41}$ que se producirían de seguirse a ciegas a quien tenga el discurso más apasionado, sin que

36 Stuart Mill, J., On Liberty, Boston, Ticknor and Fields, 1863, pp. 35-36, 100-102; Flynn, J., "Communicative Power in Habermas's Theory of Democracy", European Journal of Political Theory, vol. 3, 2004; Corte IDH, Caso Ivcher Bronstein vs. Perú, fondo, reparaciones y costas, sentencia del 6 de febrero de 2001, serie C, núm. 74, párrs. 146-155.

37 “Open Letter to ECOSOC regarding the Committee on NGOs", 24 de mayo de 2016, disponible en: https://www.hrw.org/news/2016/05/24/open-letter-ecosoc-regarding-committeengos (fecha de consulta: 27 de junio de 2016).

38 Chainoglou, K., "Psychological Warfare", Max Planck Encyclopedia of Public International Law, 2011; Kittrie, O., Lawfare: Law as a Weapon of War, Nueva York, Oxford University Press, 2016, pp. 4-60.

39 Goleman, D., Emotional Intelligence, Nueva York, Bantam Books, 1997, pp. 40, 45, 215).

40 Declaración Universal de Derechos Humanos, artículo 30.

${ }_{41}$ Kirk, E. et al., "SUDS law: Non-State Actors and the Haphazard Route to Implementation of International Obligations", Non-State Actors and International Law, vol. 4, 2004, pp. 88, 106-108. 
Esta revista forma parte del acervo de la Biblioteca Jurídica Virtual del Instituto de Investigaciones Jurídicas de la UNAM

lo dicho niegue que el discurso apasionado puede en ocasiones ofrecer la mejor alternativa.

Por estos motivos, es menester indagar sobre los discursos emotivos a través de un sólido prisma filosófico y ético. ${ }^{42}$ Esto exige a los internacionalistas y operadores jurídicos no ser reduccionistas e integrar dimensiones y elementos normativos, éticos y emotivos en sus análisis, pues de lo contrario se puede arribar a conclusiones limitadas que ignoren la panoplia de dimensiones que conviene examinar en un caso.

Se puede resumir lo discutido en esta sección diciendo que distintos actores pueden emplear estratégicamente el lenguaje y los conceptos ofrecidos por el derecho internacional de forma emotiva para promover ciertas posturas, por ejemplo, para ocultar el poco apoyo que tienen en derecho positivo o, por el contrario, para fomentar la solidaridad con las víctimas movidos por la empatía, la que es crucial en tanto puede llevar a ponerse en los zapatos de quienes sufren, incluso para exigir un cambio en el contenido o en la interpretación del derecho que les ofrezca una mayor protección que se estima justa, como puede acontecer con los llamados refugiados climáticos. ${ }^{43}$

No ha de ignorarse que muchos desarrollos y conquistas jurídicas internacionales que tanto apreciamos fueron transgresoras en términos conceptuales en un comienzo y se motivaron por la solidaridad con quien sufría. Por ejemplo, a pesar de que en su momento algunos internacionalistas prominentes afirmaron - de forma cuestionable e ignorando planteamientos teóricos previos que sí trataban a algunos como a sujetos - que los individuos, los pueblos indígenas y otros entes carecían de personalidad jurídica internacional, ${ }^{44}$ se optó de forma revolucionaria por dejar de lado esta interpretación contraproducente para ofrecer esperanza de protección tanto sustantiva como procesal a quien no la tenía a nivel interno. ${ }^{45} \mathrm{El}$ derecho internacional pue-

42 Simpson, G., op. cit., p. 21; Goldie, P., op. cit., pp. 3, 27, 232.

43 "Kiribati Climate Change Refugee Told he Must Leave New Zealand”, The Guardian, 22 de septiembre de 2015; "Has the Era of the «Climate Change Refugee» Begun?", The Washington Post, 7 de agosto de 2014; "Refugees Join List of Climate-Change Issues", The New York Times, 28 de mayo de 2009.

44 Paust, J., "Nonstate Actor Participation in International Law and the Pretense of Exclusion”, Virginia Journal of International Law, vol. 51, 2011, pp. 978, 985, 992-994); Higgins, R., Problems \& Process: International Law and How We Use it, Oxford, Oxford University Press, 2004, p. 49.

45 Voto concurrente del juez A.A. Cançado Trindade a: Corte IDH, Caso Castillo Petruzzi y otros vs. Perú, excepciones preliminares, sentencia del 4 de septiembre de 1998, serie C, núm. 41, párrs. 12, 33-35. 
Esta revista forma parte del acervo de la Biblioteca Jurídica Virtual del Instituto de Investigaciones Jurídicas de la UNAM

de, y con frecuencia debe, cambiar en su manejo o incluso en su contenido, y un análisis con inteligencia emociona ${ }^{46}$ puede sugerir de qué manera el derecho puede realmente dar protagonismo a la protección de la dignidad humana ${ }^{47} \mathrm{y}$ a bienes comunes como la protección del medio ambiente.

En consecuencia, al emplear el idioma común del derecho internacional para promover interpretaciones, aplicaciones o cambios del mismo con base en argumentos emotivos y empáticos, es posible que se genere una dinámica cosmopolita, que busca poner al individuo en el centro del derecho internacional - aunque ésta es tan solo una de las posibles dinámicas resultantes de la sinergia entre las emociones o procesos afectivos y el derecho internacional- Para que aquella dinámica no sea selectiva o excluyente ${ }^{48}$ y en consecuencia no se ignore el sufrimiento de muchos en las "periferias", hay que tener en cuenta lo revelado por estudios psicológicos relativos a los riesgos de desensibilización que se pueden generar cuando hay una excesiva exposición a sufrimientos ajenos. ${ }^{49}$ Con esto no sugiero en absoluto que se invisibilicen de forma selectiva ciertos problemas que podrían ser abordados por el derecho, sino que, por el contrario, busco resaltar la necesidad de que las estrategias emotivas que se examinan en las siguientes secciones se realicen de forma inteligente, evitando su rechazo o insignificancia.

La interacción con el derecho internacional orientada a la protección de quien sufre permite al derecho tener en cuenta sus padecimientos y buscar remediarlos en la medida de lo posible, lo cual constituye un manejo empático del mismo que no sólo es importante sino necesario, en tanto siempre hay un riesgo de que el derecho se torne estático o ignore el sufrimiento o los problemas reales, incluyendo los emotivos, de los seres humanos, como reflejan precisamente obras artísticas capaces de transmitir la vivencia de quien padece algunos límites o errores del derecho. Entre ellas, podemos mencionar la pintura titulada The Unwed Mother de Jean Louis Forain, donde se muestran abogados sin interés alguno en el drama sufrido por la madre

46 Goleman, D., op. cit., pp. 4-5, 9-11, 34, 36-45.

47 Voto concurrente del juez A.A. Cançado Trindade a: Corte IDH, Condición jurídica y derechos humanos del niño, Opinión Consultiva OC-17/02 del 28 de agosto de 2002, serie A, núm. 17, párrs. 6, 13, 18-19.

48 Halliday, F., “The Romance of Non-state Actors", en Josselin, D. y Wallace, W. (eds.) Non-state Actors in World Politics, Nueva York, Palgrave, 2001, pp. 33 y 34.

49 Burgo, J., "Got First-World Problems? Don’t Feel Guilty”, The New York Times, 2015. 
retratada $;{ }^{50}$ la novela Resurrección de León Tolstói, donde igualmente se describen jueces y operadores jurídicos sin interés alguno en el sufrimiento del personaje de Maslova, o el dramático libro El proceso de Kafka.

Precisamente, un adecuado análisis emocional y artístico del contenido y la práctica del derecho internacional pueden facilitar la identificación de algunas de sus falencias o vacíos de protección que requieran nuestros congéneres, inspirando con posterioridad iniciativas concretas y activismo cuya carga y mensajes emotivos no deben desdeñarse, pues aluden al sufrimiento y a necesidades de protección de seres de carne y hueso que sufren. Identificaciones de esta índole han inspirado movimientos que han buscado la adopción de instrumentos y normas contra minas antipersona, sobre derechos de los niños o sobre justicia penal y no impunidad, entre otros aspectos. Una influencia emocional de esta índole, empática y práctica para Simpson, es bienvenida, pues no ignora el sufrimiento que no puede ignorarse ni se queda en un mero sentimentalismo que no se traduce en una ayuda concreta requerida. ${ }^{51}$ La siguiente sección examinará, precisamente, cómo las emociones pueden desempeñar un papel relevante en los procesos de interpretación, creación y modificación normativa internacional.

\section{LA CREACIÓN E INTERPRETACIÓN EMOTIVAS DEL DERECHO INTERNACIONAL}

Como revela la acertada exposición de la policy approach de McDougal y Lasswell, sería reduccionista concebir la acción del derecho internacional limitada únicamente a su aplicación para la resolución de casos concretos, pues hay muchas otras formas, denominadas procesos, en las que el derecho internacional es empleado por diversos actores u operadores, quienes en la práctica con frecuencia actúan buscando determinados objetivos, ${ }^{52} \operatorname{los}$ que bien pueden estar motivados por emociones.

50 Véase una descripción sobre la obra en: http://artuk.org/discover/artworks/the-unwedmother-188510 (fecha de consulta: 27 de junio de 2016).

51 Simpson, G., op. cit., pp. 7, 24, 26.

52 McDougal, M. y Lasswell, H., "The Identification and Appraisal of Diverse Systems of Public Order”, American Journal of International Law, vol. 53, 1959, pp. 2, 5-6, 9-10. 
Esta revista forma parte del acervo de la Biblioteca Jurídica Virtual del Instituto de Investigaciones Jurídicas de la UNAM

Entre aquellos procesos se incluyen la terminación, modificación y creación de normas y principios, que ciertamente pueden inspirarse por la percepción de que hay vacíos o errores en el derecho internacional que lo tornan injusto, por ejemplo, cuando impiden apoyar plena o adecuadamente a quien sufre. Esto se puede hacer palpable en el proceso de deliberación sobre la adopción de nuevas normas, donde los debates o argumentos expuestos pueden tener una clara carga emotiva. Otro tanto ocurre con el proceso de decisión sobre hacer o no lo que el derecho internacional permite, tolera o estimula sin exigirlo, pues los aspectos emocionales pueden jugar un papel crucial en aquella decisión, como se expone más adelante. Evidentemente, las emociones también pueden ser decisivas cuando un destinatario pondere si respetar o no el derecho, en tanto pueden incidir consideraciones patrióticas egoístas, anhelos de venganza o la intuición de que lo regulado es obsoleto.

Algo similar puede acontecer con la invocación del derecho internacional y la exigencia de su cumplimiento por otros, pues las demandas pueden tener un trasfondo basado tanto en interpretaciones emotivas del derecho internacional como en criterios de responsabilidad social, llevando en ocasiones a quienes las presenten a asumir posturas políticas que ignoren el derecho positivo estricto para favorecer alguna noción sentimental. Claro está, la invocación del derecho presupone una valoración sobre la licitud o ilicitud internacional de una conducta, e incluso si la interpretación esgrimida por el invocador no ha sido influenciada de forma alguna por emociones, puede suceder que la razón que le lleve a exigir el respeto del derecho sea emocional, como el miedo o temor a un quebrantamiento de la legalidad internacional que pudiera generar inestabilidad. Precisamente el miedo, junto a otros tipos de emociones — rabia, tristeza, amor, placer o vergüenza - ${ }^{53}$ puede incidir en el análisis jurídico de diversas maneras.

Por ejemplo, a pesar de concluir que el uso de armas nucleares contraviene principios del derecho internacional humanitario, la Corte Internacional de Justicia afirmó que no es claro si su empleo podría ser lícito o admisible cuando la supervivencia del "Estado" esté en juego, dando una flexibilización — con la que estoy en desacuerdo - a la prohibición de aquellas armas, quizás en parte por un análisis emotivo sobre la situación que podría generarse si se exige determinada interpretación o tal vez,

53 Goleman, D., op. cit., p. 290. 
Esta revista forma parte del acervo de la Biblioteca Jurídica Virtual del Instituto de Investigaciones Jurídicas de la UNAM

como puede ocurrir con los integrantes de distintos órganos de decisión, no tanto por una reacción emotiva frente a la norma sino por emociones, como de miedo, generadas al anticiparse la posible reacción de quienes se vean afectados — directa o indirectamente - por sus pronunciamientos, lo cual puede ser relevante en derecho internacional cuando entes como los Estados pueden retirar su consentimiento en la competencia o jurisdicción de aquellos órganos o su apoyo económico.

En el anterior sentido, por ejemplo, se rumora que en Naciones Unidas se retiró a la coalición en el conflicto en Yemen liderada por Arabia Saudí de una lista de violadores de derechos de los niños en conflictos armados por la amenaza de que se eliminaría una importante ayuda humanitaria a la organización. ${ }^{54}$

Si bien las emociones pueden incidir en las distintas formas de interactuar con el derecho internacional, como su invocación, interpretación, terminación, modificación, creación o aplicación, aquella influencia no es necesariamente advertida de forma consciente. Ahora bien, ¿por qué pueden incidir en todas aquellas interacciones? Porque la interpretación del derecho abre la puerta a un posible influjo, consciente o no, de las emociones, y aquella interpretación está presente de forma ineludible en toda ocasión en la que se aplica o exige la implementación del derecho, como han dicho el profesor Remiro Brotóns y otros, ${ }^{55}$ y además en todo contacto con el mismo, incluso cuando no se busca su aplicación en adjudicación sino que se invoca para avergonzar y promover un cambio de conductas.

Por ejemplo, cuando se hace un llamado a la creación normativa para llenar vacíos que impiden una adecuada protección de quienes sufren, previamente debe haberse identificado que el derecho precisamente carece de herramientas de protección a su favor, y cuando se hacen llamados a modificar normas que se estimen como inadecuadas por no proteger de forma adecuada a las víctimas, por ejemplo, por no considerar sus necesidades emocionales, de forma subyacente hay un ejercicio de identificación de aquella carencia.

Entre las razones que permiten una posible influencia de las emociones en la interpretación del derecho internacional se puede mencionar que en

54 Lynch, C., "U.N. Chief Says He Went Soft on Saudi Arabia and Allies to Avoid Aid Cut", Foreign Policy, 9 de junio de 2016.

55 Remiro, A. et al., op. cit., p. 596. 
Esta revista forma parte del acervo de la Biblioteca Jurídica Virtual del Instituto de Investigaciones Jurídicas de la UNAM

el mismo la regla general de interpretación incluye el criterio teleológico, que llama a tener en cuenta consideraciones finalistas - que abren la puerta a cierta flexibilización- ${ }^{56}$ las que pueden tener tintes naturalistas o emotivos cuando el intérprete identifique ciertos fines meta o extrajurídicos como coincidentes con los fines de las normas que examina, cuando atribuya cualidades emotivas a los fines de las normas o cuando tenga una preferencia emocional por cierto objetivo que haga coincidir con los que supuestamente tiene una norma.

Lo anterior puede suceder, por ejemplo, cuando sus intuiciones sobre qué es la dignidad humana y las emociones que despierten en él ciertos movimientos e ideologías influyan en la manera en que perciba qué dimensiones y expresiones humanas merecen protección al considerarse fundamentales. Después de todo, las actitudes, ideología y emociones de un sujeto pueden incidir en la manera en que perciba la realidad, incluyendo la jurídica, y de esta manera pueden influir en sus operaciones de interacción con el derecho. Además, incluso el elemento literal puede ser analizado bajo un prisma emotivo que lleve a elegir entre las alternativas admisibles.

La posible influencia de las emociones en la labor interpretativa, que no es una tarea completamente "automatizada" (a diferencia de lo sugerido por algunos en la Revolución francesa y sus consecuencias) oficial o no, puede presentarse de forma consciente o inconsciente, y llevar tanto a un manejo "estratégico" de las emociones (que busca dar más solidez o efectividad $a$ una opción ya elegida racionalmente o de otra manera), por ejemplo, para generar confianza (incluso con formalismos como los ropajes de los jueces) como a una influencia en qué interpretación se elige.

Que las emociones pueden incidir en la interpretación ha sido expresado de forma convincente por Kidd White, quien dice que las emociones pueden influir, entre otras, de las siguientes maneras: facilitando la recepción de narrativas o evidencia que permitan dotar de contenido concreto en ciertos casos a las normas que protejen la dignidad humana, por ejemplo, gracias a las reacciones emocionales de rechazo a sus transgresiones; dotar a los intérpretes de claridad sobre la realidad experimentada por los implicados (por ejemplo, en relación con la alimentación forzada) y ayudarles así a percibir más fácilmente qué sentido de protección exigen ciertas normas, o para identificar los valores en la comunidad a la que pertenecen, teniendo la

56 Klabbers, J., op. cit., pp. 53 y 54. 
Esta revista forma parte del acervo de la Biblioteca Jurídica Virtual del Instituto de Investigaciones Jurídicas de la UNAM

sociedad internacional actual una interesante dimensión comunitaria, según se explica más adelante en las conclusiones de este trabajo. ${ }^{57}$

Además de lo anterior, la influencia emocional en la interpretación del derecho internacional es interesante por múltiples aspectos, incluyendo los relativos a: a) la identidad de los actores o, como diría Higgins, de los participantes que interactúan formal o informalmente con el derecho internacional; b) posibles dinámicas de confusión entre el derecho positivo y los anhelos del intérprete, y c) a la influencia de las emociones en la resolución de casos complejos, como aquellos donde hay colisión entre principios o derechos con igual jerarquía o que versen sobre las culture wars, ${ }^{58}$ en tanto en aquellos casos puede haber un — sano o riesgoso - activismo del intérprete inspirado por influencias emocionales, especialmente por el papel que pueden desempeñar el consenso, que puede ser generado por actitudes emotivas. Examinaré estas cuestiones a continuación.

Es preciso indicar que un análisis no formalista y desagregado ${ }^{59}$ que no excluya otras metodologías analíticas - permite observar que en la práctica no son sólo los agentes de los Estados y las autoridades internacionales quienes de hecho emplean y forman el derecho internacional, sino que además hay actores no estatales y subestatales ${ }^{60}$ - como el juez o abogado que busque su aplicación-, que en últimas operan por medio de seres humanos ${ }^{61}$ que interactúan con el mismo, invocándolo o promoviendo su cambio, en ocasiones por fuera de los cauces formales, ${ }^{62}$ por ejemplo mediante campañas mediáticas o de otra índole, e incluso sin tener capacidades, cargas o derechos en aquel ordenamiento jurídico.

57 Kidd White, E., op. cit., pp. 212-234.

58 Christoffersen, J., Fair Balance: Proportionality, Subsidiarity and Primarity in the European Convention on Human Rights, Leiden, Martinus Nijhoff Publishers, 2009, pp. 110 y 111; Joseph, R., Human Rights and the Uborn Child, Leiden, Martinus Nijhoff Publishers, 2009, p. 239.

59 Posner, E., op. cit., pp. 44, 64, 71-72, 78.

60 Nijman, "Non-State Actors and the International Rule of Law: Revisiting the «Realist Theory» of International Legal Personality”, Amsterdam Center for International Law Research Paper Series, Amsterdam, University of Amsterdam, 2009, pp. 9-11.

61 Principles of International Law Recognized in the Charter of the Nürnberg Tribunal and in the Judgment of the Tribunal, with Commentaries (1950: párr. 99 y Principio I).

62 Pérez-Prat, L., “Actores no estatales en la creación y aplicación del derecho internacional”, en Abellán, V. y Bonet, J. (eds.), La incidencia de la mundialización en la formación y aplicación del derecho internacional público: los actores no estatales: ponencias y estudios, Barcelona, J. M. Bosch, 2008, pp. 23-27, 30, 34-38. 
Esta revista forma parte del acervo de la Biblioteca Jurídica Virtual del Instituto de Investigaciones Jurídicas de la UNAM

Al depender la interacción del derecho en la práctica y en últimas por seres humanos, con un componente o dimensión emocional, no cabe pensar que ella carecerá de todo influjo, no necesariamente decisivo; es decir, incluso sin que se les reconozca "subjetividad" internacional de forma amplia o en absoluto - corroborando que la noción de subjetividad muchas veces se queda corta frente a la realidad internacional- ${ }^{63}$ En tanto todo actor opera por medio de individuos, la forma en que se despliega su participación hace que sus interacciones puedan explicarse, al menos parcialmente, por razones emotivas: a esto apunta Simpson cuando advierte sobre un análisis biográfico de quienes influyen en el devenir del derecho internacional, que tenga en cuenta su temperamento y sentimientos, en tanto ello puede explicar muchos de sus aportes, conclusiones o propuestas ${ }^{64}$ - y otro tanto se puede decir de todo aquel que interactúe con el derecho internacional de una u otra forma-.

La idea de que es posible una interacción indirecta de actores no estatales en procesos jurídicos internacionales, o, en otras palabras, su participación informal, ha sido confirmada por la International Law Association, que la identifica como una posible fuente "material" de aquellos procesos, lo que acontece cuando sus opiniones y acciones sirven de inspiración para los cambios y resultados de los procesos jurídicos ${ }^{65}$ Aquella inspiración o fuente material no estatal puede estar motivada en sus inicios por actitudes emotivas, o influir en los cauces formales precisamente por convencer emocionalmente a quienes detentan la posibilidad de hacer los cambios directamente o a la sociedad civil cuando esta pueda presionar a las autoridades a hacer algo.

Como ejemplo de lo anterior se pueden mencionar la conclusión normativa ex novo o la cristalización y generación ${ }^{66}$ de procesos en los que incida el derecho internacional cuando ellos son llevados a cabo en parte por la influencia de campañas promovidas por movimientos y alianzas no estatales,

63 Cortés, J., Las organizaciones internacionales: codificación y desarrollo progresivo de su responsabilidad internacional, Sevilla, Instituto Andaluz de Administración Pública, 2008, pp. 109111; Higgins, R., op. cit., pp. 49-51; Clapham, A., Human Rights Obligations of Non-State Actors, Oxford, Oxford University Press, 2006, pp. 63-73.

64 Simpson, G., op. cit., pp. 10-12.

65 International Law Association, First Report of the [Non-State Actors] Committee: Non-State Actors in International Law:Aims, Approach and Scope of Project and Legal Issues, The Hague Conference, 2010 , pp. 8 y 9.

66 Remiro, A. et al., op. cit., pp. 539-543, 552-555. 
Esta revista forma parte del acervo de la Biblioteca Jurídica Virtual del Instituto de Investigaciones Jurídicas de la UNAM

que en parte con argumentos emocionales que claman por la protección de quien sufre y por la corrección de injusticias han impulsado la adopción de instrumentos como el Estatuto de Roma de la Corte Penal Internacional; la Convención sobre la Prohibición del Empleo, Almacenamiento, Producción y Transferencia de Minas Antipersonal y Sobre su Destrucción; la Convención contra la Tortura y Otros Tratos o Penas Crueles, Inhumanos o Degradantes o la Convención sobre los Derechos del Niño. ${ }^{67}$

Aquellos ejemplos demuestran que para convencer sobre la adopción de nuevas normas puede ser útil convencer con argumentos emotivos. En la actualidad, por ejemplo, hay una campaña, promovida tanto por algunos Estados como por ONG, académicos y distintos actores no estatales, como los participantes en la Treaty Alliance, que promueve la adopción de un tratado sobre empresas y derechos humanos ${ }^{68}$ argumentando que la protección actual de las víctimas de sus abusos es insuficiente.

La influencia subestatal y no estatal cuando se apela a las emociones no tiene porqué limitarse a la creación normativa ni tiene porqué suponer una creación novedosa. Por ejemplo, en el ámbito estatal algunos jueces y abogados han promovido la protección de intereses internacionales comunitarios en escenarios de litigación transnacional o jurisdicción universal, en parte guiados por solidaridad y aprovechándose de las posibilidades que ofrece el derecho, motivados por un ánimo de luchar contra injusticias y de socorrer a las víctimas, incluso cuando un caso no guarda relación alguna con sus Estados. ${ }^{69}$ En estos casos puede jugar un papel importante la indignación frente a comportamientos que hayan sido reconocidos, precisamente por su gravedad, como crímenes internacionales, pues en caso contrario las víctimas permanecerían indefensas y los abusos impunes.

De estas y otras formas las emociones y, en concreto, la empatía y la indignación, pueden generar e inspirar movimientos y campañas que esgri-

67 Pérez-Prat, L., op. cit., pp. 28-31; Bianchi, A., "Globalization of Human Rights: The Role of Non-state Actors", en Teubner, G. (ed.) Global Law Without a State, Aldershot, Dartmouth, 1997, pp. 186-187; Amnistía Internacional, “Torture: A Global Crisis”, disponible en: https: / / www.amnesty.org/en/get-involved/stop-torture/ (fecha de consulta: 27 de junio de 2016).

68 Véase Treaty Alliance: Movimiento Global por un Tratado Vinculante, disponible en: http: / /www.treatymovement.com (fecha de consulta: 27 de junio de 2016).

69 Cassese, A., "Remarks on Scelle's Theory of "Role Splitting" (dédoublement fonctionnel) in International Law”, European Journal of International Law, vol. 1, 1990, pp. 225-230. 
Esta revista forma parte del acervo de la Biblioteca Jurídica Virtual del Instituto de Investigaciones Jurídicas de la UNAM

man que el derecho o bien es violado o es insuficiente o inadecuado a la luz de la exigencia de que se atiendan todas las necesidades de quienes sufren.

Además de esto, las emociones también pueden tener un papel importante en la transmisión de los mensaje de los distintos participantes - formales o informales - en procesos jurídicos internacionales, porque cuando sus discursos tengan tintes emotivos convincentes pueden ser más efectivos para ser seguidos y conseguir apoyo — después de todo, las emociones son importantes estímulos de comportamiento-,${ }^{70}$ por ejemplo, sobre la necesidad de que las normas o decisiones protejan adecuadamente a víctimas cuyas necesidades concretas han sido ignoradas, para satisfacer así una necesidad de especialización del derecho. ${ }^{71}$

Si no se convence en términos emotivos, la efectividad de las campañas puede no ser la esperada, confirmando que las emociones pueden ser cruciales para convencer a las autoridades o a distintos grupos sociales que pueden presionar en pro de alguna campaña. Ello confirma que las emociones pueden ser determinantes para que una iniciativa pueda erigirse como fuente material o, lo que es lo mismo, inspiración de las fuentes formales del derecho internacional. Después de todo, puede que las razones que lleven a quienes detenten la capacidad formal de crear directamente el derecho internacional sean de índole emotiva.

Como se apunta atrás, además de influir en el proceso de creación del derecho, las emociones pueden jugar un papel en otros procesos, como el de su implementación. Así, es posible que haya argumentos emotivos que determinen en qué sentido se interpreta o aplica una norma. Podemos poner los ejemplos de la cláusula Martens y sus exigencias o "leyes" de la humanidad, que pueden abrir la puerta a concepciones o influjos emotivos, o a la noción de la complicidad en crímenes internacionales, pues como se dijo en el caso Furundžija por el Tribunal Penal Internacional para la antigua Yugoslavia, puede haber complicidad por "apoyo o reforzamiento psicológico”, como acontece cuando un individuo apoye de forma simbólica o emocional a los autores de un crimen, por ejemplo, mediante su presencia

70 D’Arms, J., op. cit., p. 1467.

71 Asís Roig, R., "Hacia una nueva generalización de los derechos. Un intento de hacer coherente a la teoría de los derechos”, en Campoy, I. (coord.) Una discusión sobre la universalidad de los Derechos Humanos y la inmigración, Madrid, Dykinson, 2006, pp. 37 y 38. 
Esta revista forma parte del acervo de la Biblioteca Jurídica Virtual del Instituto de Investigaciones Jurídicas de la UNAM

cuando se entienda que apoya una conducta. ${ }^{72}$ En este caso, el análisis de las emociones de quienes despliegan determinada conducta puede ser decisivo para su calificación.

Como otro ejemplo se puede mencionar que en la determinación del monto a indemnizar por concepto de daño inmaterial o moral, al entrañar una estimación ante la imposibilidad de llegar a un monto preciso correspondiente al daño causado sin excederlo, ${ }^{73}$ pueden incidir el análisis de la afectación emocional de las víctimas y las propias emociones que despierte el análisis del caso en el evaluador. Estos ejemplos explican porqué distintos participantes pueden estar interesados en presentar argumentos emotivos mediante canales como amici curiae o en escritos doctrinales, para buscar incidir de forma más o menos directa en el devenir y la evolución - emotiva- del derecho internacional.

Además de incidir en la creación y aplicación del derecho, tener en cuenta las emociones de quienes sufren e identificarse con ellos puede contribuir al desarrollo progresivo de un derecho internacional que no ignore las necesidades emocionales de los seres humanos. Esto se revela, por ejemplo, en los progresos que se han dado frente al derecho a la verdad y a las reparaciones. ${ }^{74}$ Para quien ha padecido la pérdida de un ser querido, puede ser necesario saber tanto qué sucedió o dónde se encuentra para poder lidiar con su sufrimiento, hacer duelo e incluso perdonar. ${ }^{75}$ Por ello, son loables los avances jurisprudenciales y normativos, como los reflejados en los principios de soft law sobre reparaciones diseñados por Theo van Boven sobre el

72 Tribunal Penal Internacional para la antigua Yugoslavia, Prosecutor v. Anto Furundžija, sentencia, 10 de diciembre de 1998, párrs. 191, 205, 207, 209, 215, 232 (donde se dice, entre otros, que la presencia "psychologically strengthened" a los autores de un crimen en un caso).

73 Corte IDH, Caso Maldonado Ordoñez vs. Guatemala, excepción preliminar, fondo, reparaciones y costas, sentencia del 3 de mayo de 2016, serie C, núm. 311, párrs. 148-150; Klabbers, J., op. cit., p. 131; Corte IDH, Caso Velásquez Rodríguez vs. Honduras, reparaciones y costas, sentencia del 21 de julio de 1989, serie C, núm. 7, párrs. 37-38; Corte IDH, Caso Granier y otros (Radio Caracas Televisión) vs. Venezuela, excepciones preliminares, fondo, reparaciones y costas, sentencia del 22 de junio de 2015, serie C, núm. 293, párrs. 402-404.

74 Simpson, G., op. cit., p. 19.

75 Redress, ImplementingVictims' Rights: A Handbook on the Basic Principles and Guidelines on the Right to a Remedy and Reparation, Londres, Redress, 2006, pp. 7 y 30; ICTJ, Truth Seeking: Elements of Creating an Effective Truth Commission, Nueva York, International Center for Transitional Justice, 2013, p. 4. 
Esta revista forma parte del acervo de la Biblioteca Jurídica Virtual del Instituto de Investigaciones Jurídicas de la UNAM

derecho a conocer la verdad, ${ }^{76}$ pues dejan entrever que el derecho puede exigir que se garantice la satisfacción de necesidades emocionales.

En cuanto a las reparaciones se puede decir que toda vez que las violaciones de derechos humanos generan dimensiones de sufrimiento que no pueden resolverse exclusivamente mediante el pago de una suma de dinero, los desarrollos en las medidas de satisfacción han sido importantes, pues han llevado a la exigencia de que se adopten medidas cuyos efectos puedan aminorar o eliminar el sufrimiento y el daño inmaterial. Una mirada a algunas medidas que permiten materializar el componente de satisfacción permiten vislumbrar su dimensión emocional. Así, por ejemplo, las órdenes, cuando sean pertinentes, de erigir monumentos en honor de las víctimas, de ofrecer disculpas o de reconocer la responsabilidad, permiten alcanzar distintos objetivos con relevancia emocional: reivindicar a las víctimas públicamen$t^{77}$ y dar una sensación de que se hizo justicia, a la vez que modifican emociones negativas indebidas hacia víctimas que fueron acusadas injustamente.

Otra medida de satisfacción relevante es la orden de brindar asistencia psicológica, ${ }^{78}$ que precisamente impone la obligación al responsable de asegurarse de que las víctimas reciban una atención profesional que pueda lidiar con el daño emocional sufrido, confirmando que las consideraciones sobre las emociones de quienes estén involucrados en un caso pueden ser necesarias y decisivas para su adecuada resolución, en tanto si se ignora la dimensión emocional, que siempre está presente en toda experiencia humana, ella puede resultar inadecuada o incompleta. Precisamente, la mayor o menor amplitud que tienen las normas jurídicas, que da pie al juego de la interpretación, permite en muchos casos relativos a la protección de la dignidad humana tener en cuenta aquella dimensión, en el ejemplo descrito para determinar concretamente cómo se habrá de reparar. Tan importante es la asistencia psicológica para las víctimas, que órganos como la Comisión de la ONU que ha investigado los abusos en Siria ha solicitado a la comu-

76 Van Boven, T., "The United Nations Basic Principles and Guidelines on the Right to a Remedy and Reparation for Victims of Gross Violations of International Human Rights Law and Serious Violations of International Humanitarian Law”, United Nations Audiovisual Library of International Law, 2010, p. 5.

77 Redress, op. cit., pp. 37-39.

78 Ibidem, pp. 30, 35-36, 47, 50, 52; Van Boven, T., op. cit., p. 5; Corte IDH, Caso de la Masacre de Pueblo Bello vs. Colombia, sentencia del 31 de enero de 2006, serie C, núm. 140, párr. 274. 
Esta revista forma parte del acervo de la Biblioteca Jurídica Virtual del Instituto de Investigaciones Jurídicas de la UNAM

nidad internacional que coopere para brindarla, por ejemplo, frente a las víctimas de la comunidad yazidí. ${ }^{79}$

Dicho esto, como los distintos participantes pueden promover "su" interpretación, promoviéndola emotivamente o llegando a ella por una influencia consciente o inconsciente emocional en mayor o menor medida, existe un riesgo de que ellos confundan retóricamente la lex lata con sus posturas emotivas. Esta confusión se da cuando un participante — oficial o no- invoca el derecho internacional de una manera que no refleje lo que permite el derecho positivo. Por ello puede que haya "interpretaciones" que en realidad reflejen su concepción sobre cómo debería ser el derecho positivo. ${ }^{80} \mathrm{Cu}$ riosamente, en estos casos si la interpretación emotiva pero jurídicamente imprecisa es acogida de forma amplia y sistemática, puede que termine convirtiéndose en lex lata, en tanto el mismo en ocasiones es creado tras una violación o desconocimiento inicial del derecho positivo. ${ }^{81}$

Estas dinámicas de confusión o mezcla pueden presentarse fácilmente en el análisis de casos complejos, precisamente debido a que los mismos suelen entrañar conflictos de intereses y posturas apasionadas sobre temas cultural o políticamente debatidos. En estos casos hay una proclividad a que influyan consideraciones emotivas por dos razones: por la amplitud de las normas en cuestión y la propia dinámica de los criterios que pueden emplearse para solucionar aparentes conflictos, lo que da pie a un juego en el que se influyan argumentos con carga emocional, y porque las partes interesadas en su resolución en un sentido u otro pueden tender a revertir a argumentos emocionales para promover sus posturas, incluso cuando ello implica mezclar argumentos de lex lata y de lex ferenda y ofrecer argumentos emotivos como si reflejasen una interpretación de lo que dice o puede decir el derecho, sin que necesariamente sea así.

Por ejemplo, en temas polémicos, los distintos sistemas regionales y universales de derechos humanos acuden a distintos criterios. El sistema del Consejo de Europa acude en ocasiones — no siempre con coherencia o claridad — ${ }^{82}$ a la noción del margen de apreciación, según la cual las auto-

79 Consejo de Derechos Humanos, “They came to destroy": ISIS Crimes Against the Yazidis”, A/HRC/32 / CRP.2, 15 de junio de 2016, p. 39.

80 Bianchi, A., op. cit., p. 193-194, 201-202.

81 Treves, T., "Customary International Law", Max Planck Encyclopedia of Public International Law, 2006.

82 Shany, Y., “Toward a General Margin of Appreciation Doctrine in International Law?", 
Esta revista forma parte del acervo de la Biblioteca Jurídica Virtual del Instituto de Investigaciones Jurídicas de la UNAM

ridades estatales tienen en ocasiones una mayor amplitud, sujeta a supervisión internacional, para tomar decisiones sobre restricciones de derechos. ${ }^{83}$ Evidentemente, hay un riesgo de que las autoridades estatales hagan elecciones movidas por emociones como el odio o el temor, por ejemplo, hacia presuntos terroristas, pero el margen de apreciación no es ilimitado. Ello hace que sea interesante indagar cómo las emociones pueden determinar si aquel margen es más o menos amplio. La razón estriba en el hecho de que el Tribunal Europeo de Derechos Humanos ha considerado, no sin críticas, que entre mayores sean los consensos estatales sobre alguna cuestión, menor será el margen de apreciación, ${ }^{84}$ lo que permite, de forma interesante, que dinámicas o tendencias adoptadas e imitadas en gran parte por convicciones intuitivas o emotivas reduzcan o amplíen el margen de apreciación, más que consideraciones estrictamente normativas.

El sistema interamericano, por su parte, no ha adoptado la noción del margen de apreciación, lo que hace que las emociones puedan incidir normativamente de otra forma: no tanto en el orden político o social de los Estados, sino en el plano de los jueces y comisionados. Esto se debe a que la Corte Interamericana de Derechos Humanos, por ejemplo, prefiere optar en exclusiva por una de las alternativas en un caso complejo, imponiéndola incluso a los Estados que no sean parte en el caso mediante la figura del control de convencionalidad, ${ }^{85}$ en lugar de asumir que en ocasiones cada sociedad puede decidir dentro de ciertos parámetros. Esta opción hace que en ciertos casos complejos pueda percibirse que los órganos decisorios han cedido a lo que intuitivamente estimen como mejor o más aceptable, incluso por razones emotivas, como puede verse en el caso sobre la fecundación in vitro, pues tras criticar al Estado por defender una sola de las posturas ignorando las restantes terminó haciendo lo mismo, imponiendo una de

European Journal of International Law, vol. 16, 2006, p. 909; Benvenisti, E., "Margin of Appreciation, Consensus, and Universal Standards", International Law and Politics, vol. 31, 1999, pp. 844 y 852.

83 Shany, Y., op. cit., pp. 909-911, 922.

84 Ibidem, p. 927; Benvenisti, E., op. cit., pp. 851-853.

85 Corte Interamericana de Derechos Humanos, Control de Convencionalidad: Cuadernillo de Jurisprudencia de la Corte Interamericana de Derechos Humanos, núm. 7, San José, Corte Interamericana de Derechos Humanos, 2015. 
Esta revista forma parte del acervo de la Biblioteca Jurídica Virtual del Instituto de Investigaciones Jurídicas de la UNAM

las posturas, lo cual ha sido criticado precisamente por incurrir con ello en cierta incoherencia. ${ }^{86}$

Otro ejemplo es el de las parejas homosexuales, pues mientras el Tribunal Europeo afirmó que si bien sus integrantes tienen derechos mínimos, los Estados tienen un margen de apreciación para reconocer o no el matrimonio homosexual, el rechazo a la figura del margen ha llevado a la Corte Interamericana a sugerir que los derechos mínimos son más amplios, lo cual curiosamente ha sido cuestionado por alguno de sus jueces. ${ }^{87}$ Esta actitud del modelo americano de imponer una única solución puede explicarse por la experiencia de abusos graves en la región, pero hace que la intuición y actitudes emotivas de los integrantes de los órganos de supervisión puedan tener una mayor incidencia en la resolución de un caso. Dicho esto, las emociones pueden incidir en cualquier órgano, sistema y nivel, lo cual puede ser decisivo para cambios en la práctica jurídica, pues a pesar de carecer de stare decisis, de facto la jurisprudencia y las decisiones judiciales - $-\mathrm{y}$ cuasi judiciales - internacionales son una fuente más dinámica e influyente que lo que sugiere su denominación de auxiliar. ${ }^{88}$ Ello explica, a su vez, que distintos actores busquen influir en el devenir de la jurisprudencia, incluso con argumentos emotivos.

La influencia de las emociones en la interpretación del derecho puede facilitarse cuando haya cabida a su interpretación evolutiva, ${ }^{89}$ pues los cambios en las reacciones emotivas sociales - generales o selectivas, según convenga a la intuición del intérprete en muchos casos- pueden ser identificados como, o confundidos, con elementos normativos.

86 Paúl, A., "Corte dicta sentencia en caso de Fecundación in Vitro", en Corte IDH Blog, 14 de enero de 2013, disponible en: http: / / corteidhblog.blogspot.com.co/2013/01/corte-dictasentencia-en-caso-de.html (fecha de consulta: 28 de junio de 2016).

87 Tribunal Europeo de Derechos Humanos, Sección Primera, Caso de Schalk y Kopf vs. Austria, sentencia, 24 de junio de 2010, párrs. 61-64, 91-95; Voto parcialmente disidente del juez Eduardo Vio Grossi a: Corte IDH, Caso Duque vs. Colombia, excepciones preliminares, fondo, reparaciones y costas, sentencia del 26 de febrero de 20161 serie C, núm. 310, pp. 6-14.

88 Jackson, J., Sovereignty, the WTO, and Changing Fundamentals of International Law, Cambridge, Cambridge University Press, 2006, pp. 174 y 175; Remiro, A. et al., op. cit., pp. 518 520; Crawford, J., Brownlie's Principles of Public International Law, Oxford, Oxford University Press, 2012, pp. 37-39.

89 Corte IDH, Caso de los "Niños de la Calle”(Villagrán Morales y otros) vs. Guatemala, fondo, sentencia del 19 de noviembre de 1999, serie C, núm. 63, párr. 193; Bjorge, E., "Introducing The Evolutionary Interpretation of Treaties”, EJIL:Talk!, 15 de diciembre de 2014; Milanovic Milanovic, M., "The ICJ and Evolutionary Treaty Interpretation”, EJIL:Talk!, 14 de julio de 2009. 
Esta revista forma parte del acervo de la Biblioteca Jurídica Virtual del Instituto de Investigaciones Jurídicas de la UNAM

Otro criterio que abre la puerta a la influencia de las emociones es la consideración de que el derecho internacional no necesariamente se limita a prohibir o permitir, en tanto puede indicar que algo es tolerado" o incluso "promovido", entre otras posibilidades, como sugiere el juez Simma. ${ }^{90} \mathrm{Si}$ ello es así, concluir que el derecho hace una de estas cosas puede generar importantes efectos simbólicos o expresivos, enviando un mensaje que puede tener un impacto en la percepción cultural y emocional sobre cuán positivo es lo "promovido" e incluso generar reacciones emocionales o cambios en creencias y actitudes, ${ }^{91}$ especialmente si hay cuestiones relevantes implicadas para los destinatarios u observadores. Ello explica que algunos sectores proclives a determinada postura procuren describirla como promovida o exigida y no sólo como no prohibida, para maximizar el impacto del mensaje jurídico. Por otra parte, cuando el derecho internacional tolera, promueve o permite - por ejemplo, al no prohibir - ${ }^{92}$ algo, ello no quiere decir que el destinatario de la norma en cuestión esté obligado a desplegar la conducta admitida, lo cual hace que la influencia de las emociones pueda influir en su toma de decisiones sobre qué hacer; al igual que las emociones pueden incidir en la elección o postura electoral de los ciudadanos de un Estado, como demuestra el caso colombiano en tanto los debates y campañas a favor y en contra del plebiscito convocado para aprobar o rechazar el acuerdo entre el gobierno del presidente Santos y la guerrilla de las FARC se caracterizaron por mensajes emotivos apelando a la esperanza y reconciliación o al miedo, entre otras emociones y sentimientos.

Como ejemplo de la influencia emocional en la decisión sobre hacer o abstenerse de aquello que el derecho internacional permite (al no prohibirlo) o tolera, puede mencionarse el supuesto cuando a un Estado se le permite atacar a alguien en un conflicto armado. En este evento, el Estado no está obligado a hacerlo (salvo que la omisión constituya un hecho ilícito contrario al deber de protección de derechos humanos). De no presentarse una bifurcación entre una conducta lícita y otra alternativa ilícita, el Estado

90 Declaración del juez Simma a: Corte Internacional de Justicia, Accordance with International Law of the Unilateral Declaration of Independence in Respect of Kosovo, Advisory Opinion, I.C.J. Reports 2010, p. 403, párrs. 9-10.

91 Geisinger, A. y Ashley Stein, M., “A Theory of Expressive International Law”, Vanderbilt Law Review, vol. 60, 2000, pp. 83, 86, 88-89, 94, 97, 130-131; McAdams, R., The Expressive Powers of Law: Theories and Limits, Harvard, Harvard University Press, 2015, pp. 1-13.

92 Klabbers, J., op. cit., pp. 22 y 23. 
podrá atacar o no, y quizá las emociones pueden influir en qué deciden sus agentes, como en la disyuntiva sobre causar un daño colateral admisible jurídicamente pero concebido como moralmente "injusto" o decidir no atacar a sabiendas de que puede existir cierto riesgo en consecuencia, pudiendo jugar las emociones un papel en lo que se decida. Esto se expresa claramente en la película Eye in the $S k y,{ }^{93} \mathrm{y}$ en la siguiente sección precisamente se indaga en la influencia emocional de los filmes y otros medios en la aplicación y efectividad del derecho internacional.

\section{EL PAPEL DE LAS EMOCIONES Y LAS ESTRATEGIAS EMOTIVAS EN LA LEGITIMACIÓN Y EFECTIVIDAD DE PROCESOS JURÍDICOS INTERNACIONALES}

Acerca de la efectividad puede añadirse que, en distintos escenarios, la regulación internacional puede tener un impacto en las actitudes y la cultura de distintos actores, incluso fomentando cambios sociales y de conducta al enviar mensajes de apoyo, generando efectos expresivos o simbólicos, lo que se refuerza si hay emociones de por medio, como cuando se percibe, por ejemplo, en términos emocionales, que lo dictaminado por el derecho es legítimo desde el punto de vista de su formación y contenido. Lo anterior se relaciona con una importante dimensión práctica de la relación entre el derecho internacional y las emociones, a saber: cómo argumentos o actitudes basadas en emociones pueden incrementar o entorpecer la efectividad de aquel derecho al incrementar o cuestionar su legitimidad, y qué estrategias extra-jurídicas que apelen a las emociones pueden influir en aquella incidencia.

Dada la descentralización de la implementación del derecho internacional, que refleja aquella de la sociedad que está llamado a regular, no ha de sorprender que la observancia espontánea del derecho internacional sea un factor decisivo para su efectividad. ${ }^{94}$ Como sugiere Koh, esa observancia tenderá a ser mayor cuanto más se perciba que el contenido y las operaciones del derecho se ajustan a parámetros de legitimidad o "justicia”, los

\footnotetext{
93 Milanovic, M., "Eye in the Sky”, EJIL:Talk!, 9 de mayo de 2016.

94 Remiro, A. et al., op. cit., pp. 47-50.
} 
Esta revista forma parte del acervo de la Biblioteca Jurídica Virtual del Instituto de Investigaciones Jurídicas de la UNAM

que, como bien dicen Franck y Ratner, tienen dimensiones tanto sustantivas como procesales. ${ }^{95}$

Aunque ellos y otros autores han ofrecido planteamientos teóricos sobre qué es internacionalmente justo, la sociedad civil y los agentes de distintos actores, incluidos los Estados, tienen con frecuencia sus propias nociones de justicia de forma intuitiva y emotiva, las que pueden o no coincidir con las construcciones teóricas y en ocasiones pueden ser moldeadas por los discursos emotivos de otros actores. En cualquier caso, sus sentimientos sobre qué es justo o injusto - por ejemplo, ignorar una decisión interna que estimen "legítima" - pueden llevarles a apoyar o rechazar la implementación de normas internacionales o a buscar su transformación.

En últimas, las emociones que despierte el derecho internacional, bien por su contenido o en lo relativo a su aplicación a un caso determinado, pueden incidir en su efectividad al inspirar oposición o apoyo por parte de sus destinatarios o terceros que puedan obstaculizar su aplicación en términos políticos o de otra índole; ya algunos han considerado en el pasado que la contradicción entre los sentimientos públicos y el derecho pueden generar fricciones. ${ }^{96}$ Por otra parte, cuando las emociones frente al derecho son favorables, por ejemplo, por despertar afinidades con el mensaje transmitido por el derecho, pueden facilitar la internalización o socialización ${ }^{97}$ de los estándares internacionales.

Un ejemplo de lo descrito en el anterior párrafo se ofrece en ciertas reacciones a decisiones internacionales adversas. Es innegable y casi inevitable que, con independencia de cuán acertada sea una decisión, la parte vencida tenga sentimientos de frustración.

Sin embargo, hay riesgos cuando aquella frustración alcanza niveles de indignación, lo cual puede suceder cuando se afecten o amenacen intereses

95 Koh, H., op. cit., p. 2601; Franck, T., Fairness in International Law and Institutions, Oxford, Oxford University Press, 2002, p. 7; Ratner, S., The Thin Justice of International Law: A Moral Reckoning of the Law of Nations, Oxford, Oxford University Press, 2015, pp. 26 y 65.

96 Sajó, A., op. cit., pp. 373 y 375.

97 Goodman, R. y Jinks, D., "Incomplete Internalization and Compliance with Human Rights Law", European Journal of International Law, vol. 19, 2008, p. 726; Koh, H., op. cit., p. 2646; Capie, D., "Influencing Armed Groups: Are there Lessons to Be Drawn from Socialization Literature?", en Exploring Criteria \& Conditions for Engaging Armed Non-State Actors to Respect Humanitarian Law \& Human Rights Law Conference Report - Geneva, 4-5 June 2007, Ginebra, Geneva Call, 2008, pp. 87-89. 
Esta revista forma parte del acervo de la Biblioteca Jurídica Virtual del Instituto de Investigaciones Jurídicas de la UNAM

importantes o cuando se perciba la decisión como injusta, por ejemplo, por estimarse como arbitraria. En estos eventos, puede que la indignación lleve a la parte parcial o totalmente vencida a rechazar la decisión y a asumir incluso una actitud de "rabieta" o rebeldía, como ha sucedido con aquellos Estados que han decidido no comparecer más a procesos abiertos ante órganos como la Corte Internacional de Justicia. Esto ha acontecido, por ejemplo, con el caso de arbitraje instaurado por Filipinas contra China y resuelto en 2016 (generando, incluso anticipadamente, una airada y exagerada reacción china), y en casos contra los Estados Unidos de América y Colombia interpuestos por Nicaragua tras el rechazo de excepciones preliminares interpuestas por aquellos Estados.

En los anteriores eventos, unos son los efectos jurídicos directos de la ausencia, como la persistencia del deber de la Corte de no abstenerse y decidir sobre el fondo ${ }^{98}$ para no incurrir en omisión de sus funciones o en non liquet, y otras las implicaciones prácticas, como la posible erosión del apoyo a la Corte respectiva, que se puede materializar en potenciales retiros del reconocimiento de su competencia contenciosa o de los instrumentos que supervisa, como sucedió con los dos Estados mencionados o con Venezuela frente a la Convención Americana de Derechos Humanos - que alegó excusas infundadas que escondían el deseo de no exponerse a más críticas a sus abusos -,${ }^{99} \mathrm{o}$ incluso en posibles efectos dominó de críticas o rechazo, como sucedió con algunos chilenos que consideraron que la decisión de la Corte Internacional de Justicia en un caso entre Nicaragua y Colombia fue "salomónica", lo que a juicio de algunos, incluyendo a quienes esperaban sentencia en casos donde participaban, era inaceptable que se presentase en otras controversias, como entre Chile y Perú. ${ }^{100}$

Los anteriores escenarios corroboran que actitudes emocionales negativas frente a los procesos jurídicos internacionales redundan en contra del

98 Corte Internacional de Justicia, Militarv and Paramilitary Activities in and against Nicaragua (Nicaragua v. United States of America). Merits, Judgment. I.C.J. Reports 1986, p. 14, párrs. 26-31; artículo 53 del Estatuto de la Corte Internacional de Justicia; "Colombia respeta el derecho, pero exige también respeto al derecho”, El Tiempo, 17 de marzo de 2016.

99 Comisión Interamericana de Derechos Humanos, "CIDH manifiesta su profunda preocupación por efecto de la denuncia de la Convención Americana por parte de Venezuela”, Comunicado de Prensa, 10 de septiembre de 2013.

100 "Ex presidente de Chile: fallo favorable para Perú reactivaría demandas de Bolivia en La Haya", El Comercio, 26 de noviembre de 2012; "Lo que se juegan Chile y Perú en La Haya”, BBC Mundo, 27 de enero de 2014. 
Esta revista forma parte del acervo de la Biblioteca Jurídica Virtual del Instituto de Investigaciones Jurídicas de la UNAM

alcance y la efectividad de los sistemas internacionales, como los judiciales. Por ello, no ha de sorprender que se recurra en ocasiones al empleo de estrategias con un trasfondo emotivo que buscan el fortalecimiento del apoyo a los resultados del uso o la invocación del derecho internacional, lo cual es especialmente relevante cuando ellos persigan la protección de la dignidad humana. En tanto con aquellas estrategias se busca generar emociones favorables al derecho internacional, no ha de sorprender que incluyan iniciativas extra-jurídicas y no sólo formales.

Mediante ambas clases de estrategias se puede aspirar a la transmisión de mensajes que generen un impacto simbólico, tanto cultural como emotivo, que conlleve a apoyar los procesos de interacción con el derecho. Esos mensajes se caracterizan, en ocasiones, por la "intertextualidad" 101 o sutiles técnicas de autolegitimación o reforzamiento mutuo, ${ }^{102}$ que consisten en afirmar algo, por ejemplo, con trascendencia emocional, que sea igualmente citado o corroborado en otro momento para terminar dando un mensaje que cale en el imaginario colectivo de que esas coincidencias reflejan de forma objetiva lo que dice el derecho, sin que necesariamente sea así. Precisamente Simpson advierte sobre riesgos de esta índole, que denomina como solipsismo, en tanto pueden carecer de objetividad y ser engañosos. ${ }^{103}$

Entre las posibles estrategias extrajurídicas pueden mencionarse, entre otras, iniciativas artísticas, lúdicas y de activismo que entrañen una carga o un mensaje emocional. Algunas de ellas buscan educar sobre el derecho internacional, como puede ocurrir con videojuegos - como This War of Mine - ${ }^{104} \mathrm{o}$ aplicaciones — como Fighter not Killer - que, de forma lúdica, transmitan información sobre el contenido o la justificación del derecho internacional, por ejemplo, de las normas del DIH en lo referente a la protección debida a los civiles. ${ }^{105}$ Estos juegos pueden permitir a sus usuarios experimentar o "vivir" de forma virtual algo de lo padecido por

101 Martínez, M., "Intertextuality: Origins and Development of the Concept", Atlantis, vol. 18, 1996, pp. 268, 280-284.

102 Anderson, K., “«Accountability» as «Legitimacy»: Global Governance, Civil Society and the United Nations”, Brooklyn Journal of International Law, vol. 36, 2011, pp. 846 y 890.

103 Simpson, G., op. cit., pp. 21, 26.

104 Heller, K., "This War of Mine — A New (and Better) Type of Videogame”, Opinio Juris, 17 de noviembre de 2014.

105 Sion, N. y Bellal, A., "Mobile Technology in the Interest of Law and the Protection of Civilians, EJIL:Talk!, 29 de mayo de 2015. 
Esta revista forma parte del acervo de la Biblioteca Jurídica Virtual del Instituto de Investigaciones Jurídicas de la UNAM

víctimas reales, lo que puede fomentar su apoyo a iniciativas y demandas de su protección o de mejoras de lege ferenda, o aprender qué dice - o debería decir- el derecho. En consecuencia, las actividades lúdicas permiten educar, lo que es valioso en tanto la educación es una herramienta vital para fomentar el respeto del derecho internacional, ${ }^{106} \mathrm{y}$ tienen la ventaja de que no sólo exclusivamente teóricas sino además vivenciales. ${ }^{107}$ Por ejemplo, al ponerse en los zapatos de un torturado, como ocurre en el videojuego 1979 Revolution: Black Friday, al ver el padecimiento de los perseguidos en películas como Hotel Rwanda y Blood Diamond o al leer sobre la tortura en la novela 1984 de Orwell o sobre el genocidio (como en la novela gráfica Maus) o la desaparición forzada (por ejemplo, en el comic Enrique's Shadow del Comité Internacional de la Cruz Roja), el lector, espectador o jugador podrá "sentir" porqué es inadmisible aceptar la tortura ante el temor y sufrimiento que genera, o al asumir papeles en un juego de rol, como el famoso Dungeons \& Dragons, los jugadores podrán experimentar posibles escenarios y problemas jurídicos internacionales y su impacto en la vida de las personas, tomando decisiones sobre qué conviene hacer en estos casos, cuando en el juego se enfrenten a situaciones que entrañen preguntas de esta índole, como ocurre, por ejemplo, con Eberron, escenario que abarca aspectos sobre lucha contra la impunidad mediante un tribunal que busca sancionar criminales de guerra — examinando la disociación entre su poder simbólico y el real, por ejemplo, ante la falta de efectividad e implementación de sus órdenes de detención- - ${ }^{108}$

Así las cosas, las anteriores (y otras) estrategias pueden lograr generar empatía de forma más efectiva y directa mediante la transmisión experimental que permiten aquellos medios, contribuyendo así a generar mayor consciencia sobre las razones que explican o deben llevar a determinadas prohibiciones en normas internacionales. Esto puede tener un impacto ma-

106 Kalshoven, F. y Zegveld, L., op. cit., p. 70.

107 Véase "Programa capacitación en Aprendizaje Vivencial, Apunte Núm. 1", disponible en: http: / / www.synapsis-patagonia.com/cursos/AV/AV-APUNTE_1.pdf (última visita: 28 de junio de 2016), donde se dice: "[e]l aprendizaje vivencial es un proceso a través del cual los individuos construyen su propio conocimiento, adquieren habilidades y realzan sus valores, directamente desde la experiencia”.

108 Sobre los aspectos de Eberron discutidos, véase Wyatt, J. et al., The Forge ofWar, Estados Unidos de América, Wizards of the Coast, 2007, pp. 49, 96-98. El comic del CICR mencionado se encuentra en: https://medium.com/@ICRC/enriques-shadow-ac3a1758a3f5\#.itgtcoix2 (fecha de consulta: 1o. de septiembre de 2016). 
Esta revista forma parte del acervo de la Biblioteca Jurídica Virtual del Instituto de Investigaciones Jurídicas de la UNAM

yor o más generalizado que la sola información, en tanto no tiene un público natural restringido — los académicos o internacionalistas - y puede facilitar que las consciencias asuman compromisos o convicciones frente a la promoción o mejora de normas internacionales.

Otras estrategias que se pueden emplear persiguen la generación de presión social a favor de la adopción o implementación de normas internacionales. Esto ha ocurrido y puede canalizarse con campañas en redes sociales -YouTube, Facebook o Twitter, entre otros_-, como las llamadas Kony 2012 o la campaña \#stopKony, ${ }^{109}$ que buscan, entre otras, de forma emotiva no siempre con éxito de forma inmediata-, por ejemplo, presionar a las autoridades competentes para que detengan y se juzguen a un presunto autor de crímenes internacionales, y también aquellas que exigen mayor apoyo a los refugiados mediante mensajes transmitidos de forma emotiva, por ejemplo a través de la transmisión de imágenes de los padecimientos de algunos de ellos, la urgencia de ayudarles y respetar sus derechos. En este sentido, pueden mencionarse fotografías e imágenes que logran transmitir el drama de sus padecimientos "mejor que mil palabras", como las fotos del niño Aylan Kurdi, quien se ahogó tras el naufragio de una embarcación en la que se intentaba llegar a Grecia, o del niño Omran Daqneesh, con su imagen traumatizada tras ser rescatado de la destrucción de su hogar en un bombardeo en Alepo siendo transmitida de forma viral y como símbolo de los niños víctimas de los conflictos armados. ${ }^{110}$

El despliegue de campañas y actividades de esta u otra índole pueden - o no- entrañar un manejo emocional adecuado, que no puede llamarse manipulador cuando no hacen sino poner de manifiesto la realidad vivida por el otro, que no ha de ser ignorada; aunque sí podría entablar manipulaciones emocionales en algunos casos, cuando se intente nublar o invisibilizar argumentos racionales, ${ }^{111}$ como algunos sugieren que ocurrió con el Brexit u otras instancias de acción permitida frente a membresías u otros

109 Joyce, D. y Simm, G., “Zero Dark Thirty: International Law, Film and Representation”, London Review of International Law, vol. 3, 2015, pp. 295, 298-299; Bellantoni, C. y Polantz, K., “One Year Later: What Happened to \#stopKony?”, PBS, 19 de abril de 2013.

110 "Death of Drowned Syrian Toddler Aylan Kurdi Jolts World Leaders", The Washington Post, 3 de septiembre de 2015; "Brutal Images of Syrian Boy Drowned Off Turkey Must Be Seen, Activists Say", The New York Times, 2 de septiembre de 2015; Anne Barnard, "How Omran Daqneesh, 5, Became a Symbol of Aleppo's Suffering”, The NewYork Times, 18 de Agosto de 2016. 111 Simpson, G., op. cit., pp. 15 y 26. 
Esta revista forma parte del acervo de la Biblioteca Jurídica Virtual del Instituto de Investigaciones Jurídicas de la UNAM

aspectos, ${ }^{112}$ y como quizá ocurrió con los argumentos de la administración Bush o el candidato Trump para justificar o promover el waterboarding o invadir Irak, supuesto en el que se intentó revestir de legitimidad a un argumento jurídicamente débil sobre legítima defensa "preventiva" apelando a emociones como la sensación de urgencia y el miedo (ello recuerda igual el miedo a perder la reputación, que lleva a tantos a disfrazar sus políticas con argumentos supuestamente jurídicos, como ha dicho el profesor Remiro Brotóns). La realización de dichas campañas se facilita por la tecnología actual, que puede ser democratizadora cuando hay acceso amplio a ella y, además, sirve como herramienta de la consciencia mundial y para la implementación del derecho internacional.

Además de servir, según el caso, para convencer a ciudadanos y autoridades sobre la importancia de que se garantice lo que exige el derecho, o para tomar consciencia sobre la necesidad de su mejora de lege ferenda, los medios artísticos y lúdicos también permiten poner de manifiesto cómo con frecuencia el derecho internacional puede tener un impacto directo en la vida de muchos seres humanos. ${ }^{113}$ Esta generación de consciencia puede tener una escala global y ser incluso emocional, contribuyendo a que la sociedad civil exija a las autoridades cumplir con sus deberes internacionales o asumir mayores compromisos cuando las circunstancias lo exijan de forma urgente, por ejemplo, en materia medioambiental ante el calentamiento global.

El conocimiento empodera y, además, puede conllevar a convicciones sobre compromisos y acciones cuando se toma consciencia sobre los problemas que los demás no deberían padecer y sobre la necesidad de actuar para prevenir potenciales daños inaceptables. Por ende, un conocimiento adquirido con la transmisión de su explicación y justificación en términos tanto racionales como emotivos, que no tienen porqué estar divorciados, es doblemente fuerte, pues no es sólo intelectual, sino también vivencial. El hecho de que puede haber sinergia entre la razón y las emociones se ilustra al considerar que hay argumentos científicos sobre los riesgos medioambientales y las amenazas a muchas poblaciones, y que la solidaridad con

112 González, F., "Incendió la casa para salvar los muebles y se quedó sin casa y sin muebles", El País, 25 de junio de 2016; Milanovic, M., "Stairway to Brexit", EJIL:Talk!, 24 de junio de 2016.

113 Véase American Society of International Law, International Law: 100 Ways it Shapes Our Lives, Washington, DC, American Society of International Law, 2006. 
Esta revista forma parte del acervo de la Biblioteca Jurídica Virtual del Instituto de Investigaciones Jurídicas de la UNAM

ellos y los sentimientos sobre la necesidad de actuar ante la injusticia de su creación por la acción humana llevan a tomar acciones y asumir compromisos ante tal situación comprobada científicamente.

Cuando los argumentos se asimilan no sólo mental, sino, además, emocionalmente, los procesos de creación y promoción del derecho que haga frente a los desafíos serán percibidos con mayor legitimidad y, por ello, tendrán mayores probabilidades de éxito y presión. Así, frente a indignaciones egoístas de Estados o actores que rechacen la imposición de obligaciones o decisiones legítimas a su cargo, son útiles los argumentos que unan razón y emociones para mostrar por qué son importantes. Estos argumentos se pueden transmitir no sólo mediante textos científicos a los que acceden básicamente los académicos y practicantes del derecho internacional, sino, además, por medio de otros medios con un público más amplio, como las películas, las que según Joyce y Simm no sólo sirven para entretener, sino que, además, permiten, por una parte, materializar exigencias internacionales, por ejemplo revelando la verdad y exponiendo a los responsables ${ }^{114}$ - exigencias del componente de satisfacción en las reparaciones - incluso cuando oficialmente esto no se haga - aunque ello exige que formalmente se protejan la presunción de inocencia y otras garantías, ante posibles riesgos y daños de imagen pública-, y por la otra sirven para canalizar propuestas y denuncias, ${ }^{115}$ siendo Beasts of no Nation ${ }^{116}$ un ejemplo de ellas, en la que se muestra porqué es inaceptable que haya reclutamiento de niños y qué puede hacer la sociedad internacional frente a este crimen. En tanto el derecho internacional y los intereses y bienes jurídicos que está llamado a proteger no se limitan a los internacionalistas, su natural mayor difusión es bienvenida.

Claro está, hay riesgos de que lo transmitido en redes sociales u otros medios sea excesivamente simplificado o propaganda, incluso hegemónica o de un sector privilegiado; de que sea falso o exagerado o se preste a malentendidos — por ejemplo, sobre la "eficacia" y la "moralidad" de la tortura o de las ejecuciones extrajudiciales según lo que se podría entender "sugerido" en películas como Zero Dark Thirty, ${ }^{117}$ siendo esas conductas siempre

114 Joyce, D. y Simm, G., op. cit., pp. 295-297, 299-300, 308.

115 Ibidem, pp. 295, 298-299, 305.

116 Véase "Beasts of No Nation" en IMDb, disponible en: http://www.imdb.com/title/ tt1365050/ (fecha de consulta: 28 de junio de 2016).

117 Joyce, D. y Simm, G., op. cit., pp. 299, 308, 312, 317. 
Esta revista forma parte del acervo de la Biblioteca Jurídica Virtual del Instituto de Investigaciones Jurídicas de la UNAM

inadmisibles a mi juicio - , lo que exige que haya veracidad y contraste, y de que las películas u otros medios glorifiquen la violencia y violaciones de derechos humanos como la tortura o las ejecuciones extrajudiciales, minimizando, ignorando o incluso menospreciando los estándares internacionales y éticos, ${ }^{118}$ por ejemplo, manipulando al despertar emociones negativas hacia los terroristas o sospechosos de serlo, lo que debe combatirse con otras expresiones tanto artísticas como racionales que muestren porqué no son admisibles las violaciones contra nadie, ni siquiera contra los criminales, y mediante exposiciones objetivas de qué exige el derecho internacional, y por qué, ofreciendo argumentos convincentes tanto racionales como emocionales, para no callar o guardar silencio ante representaciones falsas o que enaltezcan o justifiquen hechos ilícitos, especialmente cuando son apoyados masivamente o por la opinión pública, lo cual debe combatirse de forma inteligente y artística (transmitiendo tanto ideas como un mensaje de empatía que muestre el sufrimiento y la justificación de garantías existentes o necesarias), entre otros, por los internacionalistas. ${ }^{119}$

El derecho internacional no puede ser frío o seco $-\mathrm{y}$ de hecho se critica con frecuencia, y emocionalmente, que pueda llegar a serlo o continuar siéndolo en algunos aspectos, lo que ha generado reacciones para "sensibilizarlo" - ${ }^{120}$ ni el monopolio de unos pocos privilegiados, estando llamado en consecuencia a servir como un lenguaje que, sin ser esclavo de algunas de ellas, tenga en cuenta las emociones y sirva como herramienta democrática para canalizar exigencias sobre un conjunto de mínimos regionales y globales. Esto explica que tampoco debe haber un divorcio entre lo que de hecho autoriza, permite o comanda el derecho (exigiendo un deber ser de conducta) ${ }^{121}$ y el deber ser del contenido jurídico según ciertas exigencias extra o metajurídicas, pues en (tantas) ocasiones lo que exige o permite el derecho debería corresponder con mínimos éticos y de empatía. La transmisión de emociones puede despertar consciencia al respecto.

118 Véase las páginas referenciadas en la anterior nota al pie y, además, las pp. 300-301, 306-307, 311, 313, 318.

119 Ibidem, pp. 312, 317-318.

120 Simpson, G., op. cit., pp. 19, 20 y 25.

121 Kelsen, H. Pure Theory of Law, op. cit., pp. 4-10; Kelsen, H., Introducción a la teoría pura del derecho, México, UNAM, 2002, pp. 19-22. 
Esta revista forma parte del acervo de la Biblioteca Jurídica Virtual del Instituto de Investigaciones Jurídicas de la UNAM

\section{CONCLUSIONES}

El derecho internacional, como producto o construcción social y humana, no es ajeno a las emociones, que conforman una dimensión de la experiencia y la actividad humanas e influyen en nuestras acciones y actitudes - incluso frente a la lex lata y la lex ferenda - al menos de forma inconsciente. No siendo lo que acontece con el derecho internacional una excepción, la actitud emocional que tengan los distintos participantes en procesos de interacción con él puede influir en sus objetivos y en su forma de interpretar el derecho internacional, pudiendo inspirar incluso los resultados de la invocación, interpretación, aplicación o modificación de las normas jurídicas internacionales de hard law o de soft law.

La interpretación siempre abre la puerta al juego de las emociones, que evidentemente no pueden ignorar de forma abierta los límites infranqueables normativos, lo cual sería un emocionalismo simplista contrario al profesionalismo ${ }^{122}$ —es preferible que se critique al derecho abiertamentepero sí pueden sutilmente expandir sus fronteras o concepción. Cuando hay una convicción emotiva sobre lo que dice o debería decir el derecho internacional, es más factible que los procesos que lo promuevan sean efectivos e interiorizados por un mayor número de personas, y por ello son bienvenidas las actitudes y mensajes empáticos frente a lo que dice o debe decir el derecho internacional, pues pueden redundar en su progresiva humanización. ${ }^{123}$

$\mathrm{Al}$ respecto, los medios de comunicación y los avances tecnológicos permiten sensibilizar hoy día a un gran número de personas sobre las exigencias normativas internacionales, reales o imaginadas, y así contribuir a la exigencia de cambios y de protección de las víctimas o de intereses comunitarios - ciertamente puede haber una dimensión comunitaria, con sus respectivos valores, en la sociedad internacional-,${ }^{124}$ por lo cual el uso de aquellos y otros medios (artísticos y lúdicos incluidos) son una importante

122 Simpson, G., op. cit., pp. 15, 20-21, 26, 28.

123 Meron, T., The Humanization of International Law, Leiden, Martinus Nijhoff Publishers, 2006, pp. xv, 86.

124 Villalpando, S., "The Legal Dimension of the International Community: How Community Interests Are Protected in International Law”, European Journal of International Law, vol. 21, 2010, pp. 418-419; Pastor, J., Curso de derecho internacional público y organizaciones internacionales, Madrid, Tecnos, 2008, p. 48; Siobhán O’Grady, “Court in Nice: Just Because 
Esta revista forma parte del acervo de la Biblioteca Jurídica Virtual del Instituto de Investigaciones Jurídicas de la UNAM

estrategia para democratizar y sensibilizar el derecho internacional, además de incrementar su efectividad: aquella sensibilización es importante, y no es sólo sentimental sino emocional al suponer una mayor evaluación crítica y comprensión de la realidad del otro y sus problemas, siendo ideal que sea empática. ${ }^{125}$

No obstante, entraña un riesgo de manipulación emocional, por ejemplo, convenciendo a algunos a reducir garantías con discursos populistas o xenófobos. Adicionalmente, no puede ignorarse que en ocasiones desarrollos en ámbitos como la tecnología o el derecho sirven como cortapisa a pasiones desmedidas como las animadas por la sed de venganza, o que es menester evitar afectar derechos cuando personas enfurecidas o apasionadas lo piden (como dijo una Corte administrativa en Francia frente al debate por la prohibición del "burkini”), lo que confirma la necesidad de tener en cuenta argumentos y técnicas racionales y complementar a las emotivas con ella, ${ }^{126}$ esta complementariedad se basa, entre otras, en la multidimensionalidad de las experiencias humanas, que tienen componentes tanto emotivos como racionales y de otra índole, siendo preciso considerarlos todos, especialmente dada la naturaleza de lo jurídico como creación social.

Por eso, un debate racional y emotivo entre distintos actores es sano y recomendable, para que el público adquiera consciencia y conozca argumentos, no sólo intelectuales, sino, además, emocionales, sobre porqué es importante que haya protección jurídica internacional - que puede generar mínimos comunes denominadores globales y regionales-, y no sólo nacional, frente a abusos e injusticias, muchas veces identificadas intuitiva y no racionalmente. Esto se facilita si se transmite la realidad emocional padecida por las víctimas y los afectados, generando empatía y solidaridad con ellos y todos los seres humanos.

En últimas, las emociones claramente pueden tener un rol en el derecho internacional, incluyendo tanto su uso estratégico en narrativas por parte de actores que buscan obtener un fin mediante ciertos usos e interaccio-

Our City Was Attacked Doesn't Mean We Can Ban Burkinis”, Foreign Policy, 1o. de septiembre de 2016.

125 D’Arms, J., op.cit., pp. 1471, 1473, 1476, 1490, 1492-1498.

126 Sajó, A., op. cit., p. 381; Wagner, M., “Autonomous Weapon Systems”, en Max Planck Encyclopedia of Public International Law, 2016; CICR, AutonomousWeapon Systems:Technical, Military, Legal and Humanitarian Aspects, Ginebra, Comité Internacional de la Cruz Roja, 2014, p. 91; Kalshoven, F. y Zegveld, L., op. cit., pp. 12-15. 
Esta revista forma parte del acervo de la Biblioteca Jurídica Virtual del Instituto de Investigaciones Jurídicas de la UNAM

nes con el derecho, facilitándose su aceptación por otros con apelaciones emotivas; como su influjo en qué hacen los participantes del derecho internacional, incluyendo aspectos como la elección de una interpretación (conscientemente o no) y la decisión sobre si hacer algo permitido o no, añadiendo aspectos como la causación de daños "proporcionales" admisibles que, a pesar de ser lícitos, no tienen una clara moralidad.

\section{BIBLIOGRAFÍA}

“Open Letter to ECOSOC regarding the Committee on NGOs", 24 de mayo de 2016.

AMERICAN SOCIETY OF INTERNATIONAL LAW, International Law: 100 Ways it Shapes Our Lives, Washington D.C., American Society of International Law, 2006.

ANDERSON, K., “«Accountability» as «Legitimacy»: Global Governance, Civil Society and the United Nations", Brooklyn Journal of International Law, vol. 36, 2011.

Andorno, R., "Human Dignity and Human Rights as a Common Ground for a Global Bioethics", Journal of Medicine and Philosophy, vol. 34, 2009.

Asís ROIG, R., "Hacia una nueva generalización de los derechos. Un intento de hacer coherente a la teoría de los derechos", en CAMPOY, I. (coord.), Una discusión sobre la universalidad de los derechos humanos y la inmigración, Madrid, Dykinson, 2006, 35-57.

Bellantoni, C. y Polantz, K., "One Year Later: What Happened to \#stopKony?”, PBS, 19 de abril de 2013.

Benvenisti, E., "Margin of Appreciation, Consensus, and Universal Standards", International Law and Politics, vol. 31, 1999.

BianchI, A., "Globalization of Human Rights: The Role of Non-state Actors", en Teubner, G. (ed.) Global Law Without a State, Aldershot, Dartmouth, 1997.

BJORGE, E., "Introducing The Evolutionary Interpretation of Treaties", EJIL: Talk!, 15 de diciembre de 2014.

Buis, E., "Law and Greek Comedy", en Fontaine, M. y SCAFuro, A. (eds.), The Oxford Handbook of Greek and Roman Comedy, Nueva York, Oxford University Press, 2014. 
Esta revista forma parte del acervo de la Biblioteca Jurídica Virtual del Instituto de Investigaciones Jurídicas de la UNAM

Burgo, J., “Got First-World Problems? Don't Feel Guilty”, The New York Times, 2015.

CAPIE, D., "Influencing Armed Groups: Are there Lessons to Be Drawn from Socialization Literature?", Exploring Criteria \& Conditions for Engaging Armed Non-State Actors to Respect Humanitarian Law \& Human Rights Law Conference Report - Geneva, 4-5 June 2007, Ginebra, Geneva Call, 2008.

Carrillo-Santarelli, N., "The Necessity and Possibility of a Binding Approach to International Corporate Human Rights Responsibilities", Quaestio Iuris, vol. 8, 2015.

y EsPÓsiTo, C., "The Protection of Humanitarian Legal Goods by National Judges", European Journal of International Law, vol. 23, 2012.

CAssese, A., "Remarks on Scelle's Theory of "Role Splitting" (dédoublement fonctionnel) in International Law", European Journal of International Law, vol. 1, 1990.

Chainoglou, K., "Psychological Warfare", Max Planck Encyclopedia of Public International Law, 2011.

Christoffersen, J., Fair Balance: Proportionality, Subsidiarity and Primarity in the European Convention on Human Rights, Leiden, Martinus Nijhoff Publishers, 2009.

CICR, Autonomous Weapon Systems: Technical, Military, Legal and Humanitarian Aspects, Ginebra, Comité Internacional de la Cruz Roja, 2014.

Clapham, A., Human Rights Obligations of Non-State Actors, Oxford, Oxford University Press, 2006.

, Human Rights: A Very Short Introduction, Oxford, Oxford University Press, 2015.

Clarke, S. et al., "The Study of Emotion: An Introduction”, en Clarke, S. et al. (eds.), Emotion, Politics and Society, Nueva York, Palgrave Macmillan, 2006.

COMISIÓn InTERAmeriCANA DE DEREChos Humanos, "CIDH manifiesta su profunda preocupación por efecto de la denuncia de la Convención Americana por parte de Venezuela”, Comunicado de Prensa, 10 de septiembre de 2013.

Consejo de Derechos Humanos, “They Came to Destroy”: ISIS Crimes Against the Yazidis", A/HRC/32 / CRP.2, 15 de junio de 2016.

CORTE IDH, Control de Convencionalidad: Cuadernillo de Jurisprudencia de la Corte Interamericana de Derechos Humanos, núm. 7, San José, Corte Interamericana de Derechos Humanos, 2015. 
Esta revista forma parte del acervo de la Biblioteca Jurídica Virtual del Instituto de Investigaciones Jurídicas de la UNAM

, Caso de la Masacre de Pueblo Bello vs. Colombia, sentencia del 31 de enero de 2006, serie C, núm. 140.

, Caso Granier y otros (Radio Caracas Televisión) vs.Venezuela, excepciones preliminares, fondo, reparaciones y costas, sentencia del 22 de junio de 2015.

, Caso Ivcher Bronstein vs. Perú, fondo, reparaciones y costas, sentencia de 6 de febrero de 2001, serie C, núm. 74.

, Caso Maldonado Ordoñez vs. Guatemala, excepción preliminar, fondo, reparaciones y costas, sentencia del 3 de mayo de 2016, serie C, núm. 311.

, Caso Velásquez Rodríguez vs. Honduras, reparaciones y costas, sentencia del 21 de julio de 1989, serie C, núm. 7.

Corte Internacional de Justicia, Militarv and Paramilitary Activities in and against Nicaragua (Nicaragua v. United States of America), Merits, Judgment. I.C.J. Reports 1986, p. 14.

CORTÉS, J., Las organizaciones internacionales: codificación y desarrollo progresivo de su responsabilidad internacional, Sevilla, Instituto Andaluz de Administración Pública, 2008.

Crawford, J., Brownlie's Principles of Public International Law, Oxford, Oxford University Press, 2012.

D’Arms, J., "Foreword: Law, Psychology, and the Emotions", Chicago-Kent Law Review, vol. 74, 2000.

"Declaración del juez Simma a: Corte Internacional de Justicia", Accordance with International Law of the Unilateral Declaration of Independence in Respect of Kosovo, Advisory Opinion, I.C.J. Reports 2010.

DWORKIN, R., "Law as Interpretation”, Critical Inquiry, vol. 9, 1982.

Estatuto de la Corte Internacional de Justicia.

Evans, D., Emotion: A Very Short Introduction, Oxford, Oxford University Press, 2003.

Feldam, H., "Foreword: Law, Psychology, and the Emotions", Chicago-Kent Law Review, vol. 74, 2000.

FlynN, J., "Communicative Power in Habermas's Theory of Democracy", European Journal of Political Theory, vol. 3, 2004.

FRANCK, T., Fairness in International Law and Institutions, Oxford, Oxford University Press, 2002.

GeIsINGER, A. y Ashley STEIn, M., "A Theory of Expressive International Law”, Vanderbilt Law Review, vol. 60, 2007. 
Esta revista forma parte del acervo de la Biblioteca Jurídica Virtual del Instituto de Investigaciones Jurídicas de la UNAM

Goldie, P., The Emotions: A Philosophical Exploration, Oxford, Oxford University Press, 2002.

Goleman, D., Emotional Intelligence, Nueva York, Bantam Books, 1997.

GONZÁLEZ, F., "Incendió la casa para salvar los muebles y se quedó sin casa y sin muebles”, El País, 25 de junio de 2016, disponible en: http://politica.elpais.com/politica /2016/06/24/ actualidad/1466763635_661285. html?id_externo_rsoc=FB_CM (fecha de consulta: 28 de junio de 2016).

GoOdman, R. y Jinks, D., "Incomplete Internalization and Compliance with Human Rights Law", European Journal of International Law, vol. 19, 2008.

Halliday, F., "The Romance of Non-state Actors", en Josselin, D. y Wallace, W. (eds.), Non-State Actors inWorld Politics, Nueva York, Palgrave, 2001.

Heller, K., "This War of Mine-A New (and Better) Type of Videogame”, Opinio Juris, 17 de noviembre de 2014.

Higgins, R., Problems \& Process: International Law and How We Use it, Oxford, Oxford University Press, 2004.

ICTJ, Truth Seeking: Elements of Creating an Effective Truth Commission, Nueva York, International Center for Transitional Justice, 2013.

InTERNATIONAL LAW ASSOCIATION, First Report of the [Non-State Actors] Committee: Non-State Actors in International Law:Aims, Approach and Scope of Project and Legal Issues, The Hague Conference, 2010.

JACKSON, J., Sovereignty, the WTO, and Changing Fundamentals of International Law, Cambridge, Cambridge University Press, 2006.

Joseph, R., Human Rights and the Uborn Child, Leiden, Martinus Nijhoff Publishers, 2009.

Joyce, D. y Simm, G., "Zero Dark Thirty: international law, film and representation”, London Review of International Law, vol. 3, 2015.

Kalshoven, F. y Zegveld, L., Constraints on theWaging ofWar, Ginebra, Comité Internacional de la Cruz Roja, 2001.

KELSEN, H., Introducción a la teoría pura del derecho, México, UNAM, 2002. 2008.

KIDD White, E., “Till Human Voices Wake Us”, Journal of Law, Religion and State, vol. 3, 2012. 
Esta revista forma parte del acervo de la Biblioteca Jurídica Virtual del Instituto de Investigaciones Jurídicas de la UNAM

KIRK, E. et al., "SUDS Law: Non-State Actors and the Haphazard Route to Implementation of International Obligations", Non-State Actors and International Law, vol. 4, 2004.

KITTRIE, O., Lawfare: Law as a Weapon ofWar, Nueva York, Oxford University Press, 2016.

KlabBers, J., International Law, Cambridge, Cambridge University Press, 2013.

KOH, H., "Why Do Nations Obey International Law?", The Yale Law Journal, vol. 106, 1997.

Koskenniemi, M. "Histories of International Law: Significance and Problems for a Critical View", Temple International and Comparative Law Journal, vol. 27, 2013.

LEE, T. "International Law, International Relations Theory, and Preemptive War: The Vitality of Sovereign Equality Today", Law and Contemporary Problems, vol. 67, 2004.

Losano, M., "Towards a Common Good: A Path to Utopia? From Philosophy through Legislation to the Dignified Life", European Journal of Law Reform, vol. 6, 2004.

Lynch, C., "U.N. Chief Says He Went Soft on Saudi Arabia and Allies to Avoid Aid Cut", Foreign Policy, 9 de junio de 2016.

MartíneZ, M., "Intertextuality: Origins and Development of the Concept”, Atlantis, vol. 18, 1996.

MCADAms, R., The Expressive Powers of Law: Theories and Limits, Harvard, Harvard University Press, 2015.

McDougal, M. y Lasswell, H., "The Identification and Appraisal of Diverse Systems of Public Order”, American Journal of International Law, vol. 53, 1959.

MEERNIK, J. et al., "The Impact of Human Rights Organizations on Naming and Shaming Campaigns", Journal of Conflict Resolution, vol. 56, 2012.

Meron, T., The Humanization of International Law, Leiden, Martinus Nijhoff Publishers, 2006.

MilanoviC, M., "The ICJ and Evolutionary Treaty Interpretation", EJIL: Talk!, 14 de julio de 2009.

, "Eye in the Sky", EJIL:Talk!, 9 de mayo de 2016.

, "Stairway to Brexit", EJIL:Talk!, 24 de junio de 2016.

Miller, D., Political Philosophy: A Very Short Introduction, Oxford, Oxford University Press, 2003. 
Esta revista forma parte del acervo de la Biblioteca Jurídica Virtual del Instituto de Investigaciones Jurídicas de la UNAM

NiJMAN, "Non-State Actors and the International Rule of Law: Revisiting the «Realist Theory» of International Legal Personality", Amsterdam Center for International Law Research Paper Series, Amsterdam, University of Amsterdam, 2009.

PASTOR, J., Curso de derecho internacional público y organizaciones internacionales, Madrid, Tecnos, 2008.

Paúl, A., "Corte dicta sentencia en caso de Fecundación in Vitro", en Corte IDH Blog, 14 de enero de 2013, disponible en: http: / / corteidhblog.blogs pot.com.co/2013/01/corte-dicta-sentencia-en-caso-de.html (fecha de consulta: 28 de junio de 2016).

PAust, J., "Nonstate Actor Participation in International Law and the Pretense of Exclusion”, Virginia Journal of International Law, vol. 51, 2011.

PÉREZ-PRAT, L., “Actores no estatales en la creación y aplicación del derecho internacional", en ABELLÁN, V. y BONET, J. (eds.), La incidencia de la mundialización en la formación y aplicación del Derecho Internacional Público: Los actores no estatales: Ponencias y estudios, Barcelona, J. M. Bosch, 2008, $21-38$.

Posner, E., The Perils of Global Legalism, Chicago, The University of Chicago Press, 2009.

Principles of International Law recognized in the Charter of the Nürnberg Tribunal and in the Judgment of the Tribunal, with commentaries (1950).

Ratner, S., The Thin Justice of International Law: A Moral Reckoning of the Law of Nations, Oxford, Oxford University Press, 2015.

REDRESS, Implementing Victims' Rights: A Handbook on the Basic Principles and Guidelines on the Right to a Remedy and Reparation, Londres, Redress, 2006. Remiro, A. et al., Derecho internacional, Valencia, Tirant lo Blanch, 2007.

SAJÓ, A., "Emotions in constitutional design", International Journal of Constitutional Law, vol. 8, 2010.

SENSEN, O., "Human dignity in historical perspective: The contemporary and traditional paradigms", European Journal of Political Theory, vol. 10, 2011.

SHANY, Y., "Toward a General Margin of Appreciation Doctrine in International Law?", European Journal of International Law, vol. 16, 2006.

Simpson, G. "The Sentimental Life of International Law", London Review of International Law, vol. 3, 2015.

Sion, N. y Bellat, A., "Mobile Technology in the Interest of Law and the Protection of Civilians, EJIL:Talk! , 29 de mayo de 2015. 
Esta revista forma parte del acervo de la Biblioteca Jurídica Virtual del Instituto de Investigaciones Jurídicas de la UNAM

Stuart Mill, J., On Liberty, Boston, Ticknor and Fields, 1863.

TiCEHuRST, R., "La cláusula de Martens y el derecho de los conflictos armados", Revista Internacional de la Cruz Roja, 31 de marzo de 1997.

TolstóI, L., What is Art, Indianápolis, Hackett Publishing Company, Inc., 1996.

Treves, T., "Customary International Law”, Max Planck Encyclopedia of Public International Law, 2006.

Tribunal Europeo de Derechos Humanos, Sección Primera, Caso de Schalk y KopfVs. Austria, sentencia del 24 de junio de 2010.

Tribunal Penal InTERnacional PARA la AnTigua YugOSLAVIA, Prosecutor v. Anto Furundžija, sentencia del 10 de diciembre de 1998.

Tumonis, "Legal Realism \& Judicial Decision-Making”, Jurisprudencija / Jurisprudence, vol. 19, 2012.

VAn Boven, T., "The United Nations Basic Principles and Guidelines on the Right to a Remedy and Reparation for Victims of Gross Violations of International Human Rights Law and Serious Violations of International Humanitarian Law", United Nations Audiovisual Library of International Law, 2010.

VillalPANDO, S., "The Legal Dimension of the International Community: How Community Interests Are Protected in International Law", European Journal of International Law, vol. 21, 2010.

Voto concurrente del juez A.A. Cançado Trindade a: Corte IDH, Caso Castillo Petruzzi y otros vs. Perú, excepciones preliminares, sentencia del 4 de septiembre de 1998, serie C, núm. 41.

Voto concurrente del juez A.A. Cançado Trindade a: Corte IDH, Condición jurídica y derechos humanos del niño, Opinión Consultiva OC-17/02 del 28 de agosto de 2002, serie A, núm. 17.

Voto parcialmente disidente del juez Eduardo Vio Grossi a: Corte IDH, Caso Duque vs. Colombia, excepciones preliminares, fondo, reparaciones y costas, sentencia del 26 de febrero de 2016, serie C, núm. 310.

Voto razonado del juez A.A. Cançado Trindade a: Corte IDH, Caso Bámaca Velásquez vs. Guatemala, fondo, sentencia del 25 de noviembre de 2000, serie C, núm. 70.

Wagner, M., "Autonomous Weapon Systems”, Max Planck Encyclopedia of Public International Law, 2016.

WyATT, J. et al., The Forge ofWar, Estados Unidos de América, Wizards of the Coast, 2007. 